\author{
$2018-07-23$ \\ icade núm. 102 [Revista cuatrimestral de las Facultades de Derecho y Ciencias Económicas y \\ Empresariales] \\ Monográfico \\ Pobreza energética \\ Artículos \\ 1. La pobreza energética en la Unión Europea y el Reino Unido (MACARENA LARREA BASTERRA)
}

\title{
Artículos
}

\section{La pobreza energética en la Unión Europea y el Reino Unido*)}

\section{MACARENA LARREA BASTERRA}

Investigadora Orkestra-Fundación Deusto, Deusto Business School, Universidad de Deusto (macarena.larrea@orkestra.deusto.es)

Sumario:

I. Introducción

II. La dificultad de encontrar consenso en la UE sobre el concepto «Pobreza energética»

1. Sobre la evolución del término pobreza energética en la UE y los consumidores vulnerables

2. Pobreza energética y consumidores vulnerables en el sector energético de la UE. Medidas de protección a clientes vulnerables y para abordar la pobreza energética

3. La pobreza energética en la UE

III. Reino Unido: líder en la conceptualización y la lucha contra la pobreza energética

1. Dos indicadores, cuatro naciones

2. La energía en el Reino Unido: suministro, precios, consumo doméstico y factura energética

3. La pobreza energética en el Reino Unido: cuatro naciones cuatro planteamientos
3.1. Irlanda del Norte
3.2. Gales
3.3. Escocia
3.4. Inglaterra

IV. Conclusiones

Bibliografía

RESUMEN: La pobreza energética es una realidad en Europa a pesar de que haya países donde no se reconozca, hasta el punto de no contar con una definición para ella. Sin embargo, su identificación a nivel comunitario está avanzando y resulta conveniente avanzar hacia un mecanismo de medición homogéneo. El Reino Unido por su parte, podría considerarse líder en esta materia dada la involucración tanto del Gobierno Central como de las naciones en la medición de la pobreza energética y en el desarrollo de medidas y planes para su erradicación. La eficiencia energética se ha convertido en uno de los principales pilares de estos planes.

PALABRAS CLAVE: pobreza energética \# eficiencia energética\# indicadores\# medidas \#UE \# Reino Unido

\section{ENERGY POVERTY IN THE EUROPEAN UNION AND IN UNITED KINGDOM}

ABSTRACT: Energy poverty is a reality in Europe even if there are countries where it is not recognized and where there is not a definition for it However, its recognition at Community level is progressing and it should be convenient to move towards a homogeneous measuremen mechanism. The United Kingdom, for its part, could be considered a leader in this area given the involvement of both the Central Government and nations' in the measurement of energy poverty and in the development of measures and plans for its eradication. Energy efficiency has become one of the main pillars of this fight against energy poverty

KEYWORDS: Energy poverty \# energy efficiency \# indicators\# measures\# EU \# United Kingdom

Fecha de recepción: 20/09/2017

Fecha de aceptación: 18/12/2017

\section{INTRODUCCIÓN}

La energía es un servicio de interés general, por lo que debe garantizarse su accesibilidad, asequibilidad y continuidad de suministro (EANp, 2010). Sin embargo, la crisis económica y el aumento de los precios de la energía han llevado a los titulares el concepto de pobreza energética, que ya se veía como problema hace más de una década a nivel comunitario y desde los años 70 en el Reino Unido.

Sin embargo, de acuerdo con Bourasovski et al. (2012), poca investigación se ha realizado en los países de la Unión Europea (UE), sobre el tema de la pobreza energética salvo en el Reino Unido (DAmianova, 2015) e Irlanda, que tienen una extensa trayectoria en este ámbito. Es más, apenas un tercio de los países de la UE reconocen oficialmente la pobreza energética u ofrecen una definición de la misma. A pesar de ello, parece que se están realizando esfuerzos por abordar la pobreza energética y los consumidores vulnerables, aunque en diferente medida en los distintos países. Ahora bien, ¿qué es la pobreza energética?

Existe una gran literatura desarrollada alrededor de este concepto y su definición. Es más, en inglés, existen dos términos: pobreza energética y fuel poverty, que si bien algunos autores emplean indistintamente (BouRzarovski et al., 2015), para otros muestran elementos diferenciadores. Así, 
de acuerdo con la Comisión Europea, por el momento y mientras se desarrolla un consenso, la pobreza energética se refiere a los costes de la electricidad y el gas, mientras que fuel poverty tiene en cuenta todas las fuentes energéticas (EC, 2010). Para otros, se produce pobreza energética en países relativamente ricos con climas fríos y fuel poverty en climas variados pero, principalmente, en países pobres (BouzARovsKi et al., 2015).

Las primeras definiciones de lo que es la pobreza energética datan de los años 70, si bien no es hasta 1991, cuando Brenda Boardman la definió específicamente, refiriéndose como "pobres energéticos» a aquellos hogares cuyo gasto en energía y servicios energéticos suponía más de un $10 \%$ de sus ingresos (Moore, 2012). Con el tiempo, esta primera definición fue ajustándose, introduciendo elementos como la necesidad de una "calefacción adecuada".

En opinión de BOARDMAN (2010), hay pobreza energética cuando los hogares no disponen de recursos suficientes para cubrir las necesidades más básicas de energía como calentar, iluminar, cocinar y usar otros electrodomésticos, lo que incluye todas las fuentes energéticas. De acuerdo con la Agencia Internacional de la Energía (IEA por sus siglas en inglés), el término pobreza energética reconoce la falta de acceso a los servicios básicos de energía, como la electricidad o los «equipamientos de cocina limpios». Ello es debido a una combinación de equipamiento deficitario, edificios inadecuados, elevados precios de la energía y reducidos ingresos. Por ello, para medir la pobreza energética, se requiere además un conocimiento detallado del parque inmobiliario.

Otros factores adicionales serían consumos energéticos por encima de la media como señalan SNELL et al. (2015), así como la ausencia de ahorros en las facturas en el caso de las viviendas alquiladas, que no incitan al propietario a emprender medidas de ahorro energético según BoARDMAN $(2010)^{1)}$. Ante esta situación los hogares tienen dos alternativas. La primera consiste en gastar por encima de la media en energía y la segunda prescindir de este producto esencial.

En lo que a medidas para solucionar el problema se refiere, la mayoría de ellas presentan un enfoque a corto plazo, aunque abordar la pobreza energética requiere también una visión a largo plazo, al involucrar entre otros, medidas de eficiencia energética (EE) y otras cuestiones de carácter estructural.

En este documento se va a realizar una revisión del estado de la pobreza energética a nivel comunitario. En efecto, y como se acaba de señalar, resulta de interés observar que no todos los países de la UE aceptan su existencia en el interior de sus fronteras; además, entre aquellos que la reconocen, no todos abordan su cuantificación de la misma manera y no todos enfocan la solución a esta situación con el mismo tipo de medidas. No obstante, la UE ha señalado que todos los Estados miembros, deberán contar con una definición, que se ajuste a la realidad e idiosincrasia de cada uno. A continuación se analizará el caso del Reino Unido, como país precursor de la investigación en este tema y, en particular, el caso de Inglaterra, como territorio que más ha avanzado en la definición y cuantificación clara de lo que se considera pobreza energética.

\section{LA DIFICULTAD DE ENCONTRAR CONSENSO EN LA UE SOBRE EL CONCEPTO "POBREZA ENERGÉTICA»}

En 2008, más de 80 millones de personas vivían en la UE por debajo del umbral de la pobreza²), es decir, una población superior a la del Estado miembro más grande, o el equivalente al 16,5\% de la población europea. Además, la crisis ha afectado a las personas más vulnerables de la sociedad. Como consecuencia, la Comisión Europea ha hecho de la lucha contra la pobreza un elemento clave de su agenda económica, laboral y social: la Estrategia Europa 2020 (Plataforma Contra la Pobreza, 2011).

De acuerdo con la encuesta de la Unión Europea sobre ingresos y condiciones de vida ${ }^{3}$ en 2012, aproximadamente 54 millones de ciudadanos europeos (un 10\% de la población europea) no tenían un adecuado acceso a los recursos energéticos (DAmianova, 2015). En 2016, esta cifra se situaba en un 11\% (EPSU, EAPN, 2017).

La definición de pobreza energética, en este caso, se aplica a aquellos individuos que no tienen acceso a suficientes recursos energéticos para sus hogares, a un coste asequible debido a tres factores: ingresos reducidos, reducida eficiencia térmica de los edificios y elevados costes energéticos, como se observa en la siguiente figura.

En este sentido, se entiende que hay dos tipos de pobreza energética. El primero podría definirse en términos de la desigualdad y afecta fundamentalmente a los hogares más pobres con viviendas menos eficientes. El segundo se referiría a la pobreza en cuanto a la accesibilidad a una energía asequible, que afecta no solo a los hogares con mayor nivel de consumo energético, sino también a aquellos con ingresos medios-bajos cuyo presupuesto para la adquisición de energía se ve menguado conforme el precio de la misma sube (DuBois y MEIER, 2014).

Figura 1. Principales indicadores de pobreza energética 


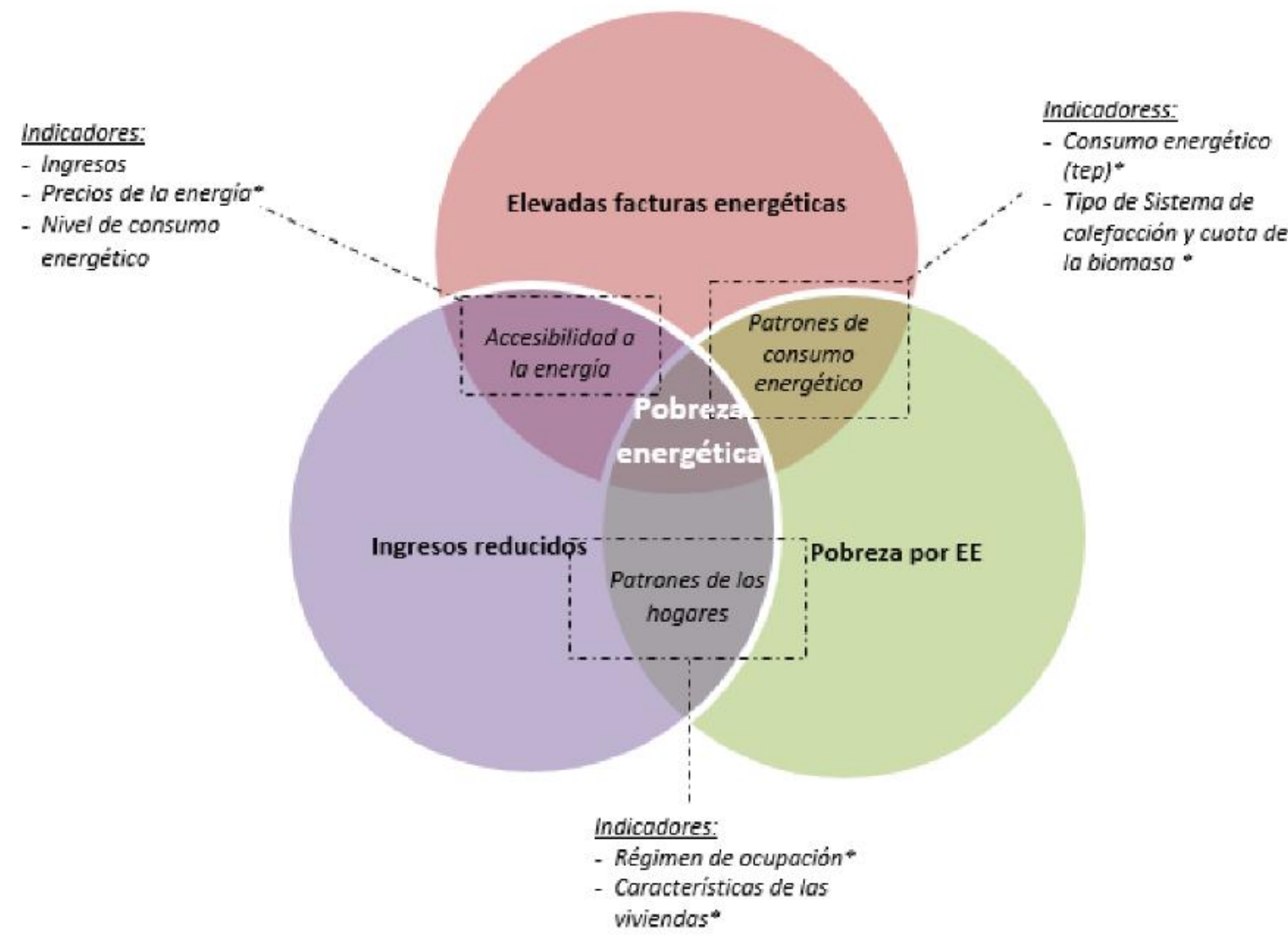

*: indicador exógeno

Fuente: Pye et. al., 2015a, p. 10.

En otros casos, se ha considerado la pobreza energética como la incapacidad de calentar la vivienda de una determinada manera a un coste razonable (EAPN, 2010). También conviene señalar que la privación ${ }^{4)}$ de energía no solo afecta a la calefacción, sino también a la disposición de agua caliente sanitaria, refrigeración, iluminación, cocina, etc. En todo caso, la pobreza energética también se vincula a la vulnerabilidad de los consumidores que, pueden ser vulnerables en este sentido, y también porque no son capaces de acceder a los mercados de electricidad y gas (Damianova, 2015).

La vulnerabilidad y la pobreza energética comparten elementos comunes como los reducidos ingresos y la baja calidad del parque inmobiliario, pero los hogares pobres en términos energéticos deben de afrontar otros aspectos de vulnerabilidad como la calidad de la vivienda y las circunstancias sociales e individuales específicas.

En la actualidad, la pobreza energética se entiende como resultado de «una condición más extensa y difusa de vulnerabilidad energética, definida como la probabilidad de un hogar de experimentar una situación en virtud de la cual, el hogar no recibe una cantidad adecuada de servicios energéticos»5). De esta manera, la pobreza energética podría entenderse como un estado temporal causado por condiciones estructurales y coyunturales que van más allá de los tres indicadores recogidos en la figura anterior (TiRADo HERRERo et al., 2016).

Todo lo anterior debería urgir a las instituciones comunitarias a que, junto con los Estados miembros, se reconozca y defina la pobreza energética y la vulnerabilidad de los consumidores como un primer paso para luchar contra ella.

En la práctica, son muchas las instituciones y comités que han abogado y abogan por que se establezca una definición común del concepto pobreza energética. Sin embargo, la Comisión Europea ha expresado que no respalda una definición común europea del término ya que no resultaría apropiada por la diversidad de contextos energéticos que existe en el conjunto de la Unión.

No obstante, mientras se promociona la competencia en los mercados energéticos, el desarrollo de las renovables, etc., los Gobiernos y los reguladores tienen la función de proteger a las comunidades más vulnerables y de prevenir que determinados grupos de la sociedad caigan en pobreza energética (Pye et. al., 2015b).

\section{SOBRE LA EVOLUCIÓN DEL TÉRMINO POBREZA ENERGÉTICA EN LA UE Y LOS CONSUMIDORES VULNERABLES}

En lo que a la evolución del término pobreza energética se refiere, en la UE se pueden distinguir cuatro periodos: 2001-2006, 2007-2010 y 201120146); seguidos del período 2015-actualidad.

Entre 2001 y 2006 se mencionó el término pobreza energética ( fuel poverty) en doce documentos comunitarios, sin embargo, únicamente en dos de ellos se hacía referencia a países de la UE. Es decir, hasta ese momento, el problema de la pobreza energética se planteaba en otros países fuera de la Unión.

La primera vez que se hizo referencia a este término, aplicado a la UE, fue en 2001, en un documento de opinión del Consultative Committee of the European Coal and Steel Community (ECSC), aunque no recogía su significado. 
En 2003, la Comisión Europea citó el término por vez primera, expresando que se trataba de una competencia de política energética que recaía en los Estados miembros. Además, citaba otro término muy relacionado con este que es el de consumidor vulnerable ( vulnerable customer ), sin establecer distinciones ni solapes entre ellos.

En el mismo año dos Directivas europeas (2003/54/CE ${ }^{7}$ y 2003/55/CE $\left.{ }^{8}\right)$ introducían el concepto de consumidor vulnerable en el ámbito legal, en el contexto del mercado interno de la energía, esbozando además medidas de protección para clientes residenciales relacionadas con el pago de facturas y otras relacionadas con la Seguridad Social.

En el período posterior (2007-2010), se produjo un reconocimiento legal del término, aunque no vinculante. De esta manera, a partir de 2007, tanto fuel poverty como energy poverty aparecían como preocupaciones recurrentes en los documentos de política europea, en particular durante las etapas preparatorias de las Directivas 2009/72/CE y 2009/73/CE, sobre normas para el mercado interior de electricidad y gas, respectivamente, que suponían un reconocimiento legal de la pobreza energética.

En este sentido, en 2008 el Parlamento Europeo propuso enmiendas al borrador de estas Directivas de Mercado interno, incorporando párrafos que describían energy poverty 9) y energy affordability 10). Asimismo, planteó otra enmienda que exigía a los Estados miembros generar definiciones nacionales de pobreza energética y planes de acción para resolver el problema, sin que las medidas interfirieran en el desarrollo del mercado interno de la energía.

Sin embargo, estas enmiendas fueron rechazadas por el Consejo Europeo, que expresó que no defendería una definición de pobreza energética por parte de la UE.

Es decir, a pesar de que la Comisión reconocía la pobreza energética y la inacción de los Estados miembros al respecto, así como la falta de protección a los clientes vulnerables, no se emitió ningún documento legalmente vinculante. Por el contrario, se optó por publicar una carta ( charter ), lo que fue criticado por la EESC ${ }^{11)}$. En esta carta, se abordó la necesidad de aumentar los derechos de los consumidores vulnerables y de compensar el mercado, así como la orientación a la competencia en la UE (EAPN, 2010).

Finalmente, en las Directivas 2009/72/EC ${ }^{12)}$ y 2009/73/EC ${ }^{13)}$, legalmente vinculantes, se incluyeron como requisitos el desarrollo de planes de acción nacionales y la prohibición de desconexión ante impagos. Es decir, en ellas se reconocía el problema creciente que se estaba planteando en la UE (Dubois y MAER, 2014a). Sin embargo, cabe señalar que, como consecuencia de esta normativa, solo los consumidores de gas y electricidad están protegidos por la ley.

El período entre 2011 y 2014 se caracterizó por una creciente preocupación por los temas de pobreza energética y de combustibles así como por los consumidores vulnerables, incluyéndose el término pobreza energética en el Tercer Paquete de Energía así como en un gran número de documentos adoptados por diferentes organismos (BouZARovski et al., 2015). De esta manera, en 2012 se publicó la Directiva 2012/27/EC ${ }^{14)}$ que reconocía la existencia de pobreza energética y consumidores vulnerables, y recomendaba vincular financiación a la eficiencia energética.

Llegado este punto, uno de los principales problemas que se planteaban era la confusión de los términos consumidores en riesgo de pobreza energética y consumidores vulnerables. Una persona en riesgo de pobreza energética puede ser un consumidor vulnerable, pero no necesariamente todos los planes de acción para consumidores vulnerables cubren a personas en riesgo de pobreza energética. Es decir, hay casos, en los que el estatus de consumidor vulnerable se debe únicamente al hecho de que recibe una ayuda por desempleo o una pensión.

Como consecuencia del Tercer Paquete de Energía, se esperaba que los países desarrollaran Planes de Acción Nacional en Energía que recogieran acciones relacionadas con la pobreza energética y se mejorara la protección de los consumidores vulnerables y su definición (EAPN, 2010).

Un año más tarde, en 2013, el Vulnerable Consumer Working Group (VCWG) publicó una guía, donde concluyó que no era posible tener una definición única en la UE de «consumidor vulnerable» pero, en su lugar, proponía elaborar una lista de potenciales factores impulsores de dicha vulnerabilidad, lo que tenía la ventaja de que ampliaba el alcance más allá de los principales factores reconocidos causantes de la pobreza energética: ingresos de los hogares, EE y precios de la energía.

En 2014, el Comité de las Regiones (CoR) trabajó en el alcance de la pobreza en Europa y las medidas para aliviarlo, señalando la necesidad de contar con una definición flexible, en función de las diferentes y diversas circunstancias de los Estados miembros y de sus regiones.

Más recientemente, el Citizen's Energy Froum (CEF) y la Comunicación del paquete de la Unión de la Energía de febrero de 2015 animaron a la protección de los consumidores vulnerables (Damianova, 2015). En este sentido, la Comisión y los Estados miembros deben mejorar la operación y el diseño de los mercados energéticos, con el fin de promocionar la sostenibilidad de los recursos y, a la vez, garantizar al consumidor protección y poder de compra en el ámbito energético.

De acuerdo con Damianova (2015) es necesario que la Comisión y los Estados miembros trabajen conjuntamente en la búsqueda de una definición de pobreza energética y de consumidores vulnerables con el fin de afrontar los retos que se plantean a través de las estrategias y políticas adecuadas y mediante la implementación de las medidas correspondientes. Es más, hay que tener en cuenta que el desarrollo de normativa en el ámbito energético, como ha sido la liberalización del mercado energético, la promoción de renovables o el desarrollo futuro de nuevos tributos energéticos como en los países nórdicos o de una nueva fiscalidad verde, pueden tener un impacto social considerable, en particular sobre los consumidores más vulnerables (EAPN, 2010). Y, como se ha comentado, pobreza energética y vulnerabilidad no son lo mismo. Las últimas Directivas, incluyen una asunción implícita de que los consumidores vulnerables también pueden ser vulnerables a la adquisición de energía (Pye et al., 2015a).

A modo de conclusión, se puede decir que la normativa comunitaria actual, reconoce la existencia de pobreza energética y su incremento; pero permite a los Estados miembros eludir su responsabilidad y no dar protección al consumidor. A pesar de ello, el Parlamento Europeo, EESC y CoR están solicitando una definición general que cada Estado adapte a su contexto local. No obstante, hay autores que consideran que, como consecuencia de las especificidades institucionales de cada país europeo, una definición de pobreza energética que sirva a todos no parece factible (DubOIS Y MAYER, 2014a).

\section{POBREZA ENERGÉTICA Y CONSUMIDORES VULNERABLES EN EL SECTOR ENERGÉTICO DE LA UE. MEDIDAS DE PROTECCIÓN A CLIENTES} VULNERABLES Y PARA ABORDAR LA POBREZA ENERGÉTICA

Como se ha comentado, no existe un consenso sobre lo que se concibe como pobreza energética, es más, ni siquiera todos los países de la UE cuentan con una definición de este concepto. Eso sí, a pesar de todo, la Comisión Europea exige a los Estados miembros reconocer y definir qué se entiende en cada contexto nacional por consumidor vulnerable. Entre los Estados, algunos lo definen explícitamente, otros de forma implícita y pocos están aún desarrollando una definición. Entre aquellos que sí lo han definido, existen opiniones diferentes respecto a cómo tipificarlos, es decir, si la definición se basa en una cuestión de asequibilidad de la energía, grupos socioeconómicos, grupos de personas por su estado de salud, etc.

A su vez, entre las primeras medidas que se pueden adoptar, de tipo social o energético, para solventar la situación de estas personas en vulnerabilidad o pobreza energética, se encuentran medidas de ayuda económica, de mejora de la eficiencia energética, de concienciación o información, de protección (por ejemplo ante el corte del suministro energético por impagos de las facturas), o una combinación de las anteriores, entre otras.

La siguiente tabla sitúa a los diferentes países de la UE-28 en función de si cuentan o no con una definición de pobreza energética, si tienen 
definición de vulnerabilidad y en base a qué criterios y, finalmente, el color y formato de la letra indican el tipo de medidas primarias adoptadas para la protección del consumidor.

Tabla 1. Análisis por país de su situación frente a la definición o no de la pobreza energética y la vulnerabilidad de los consumidores. Principales medidas adoptadas en primera instancia

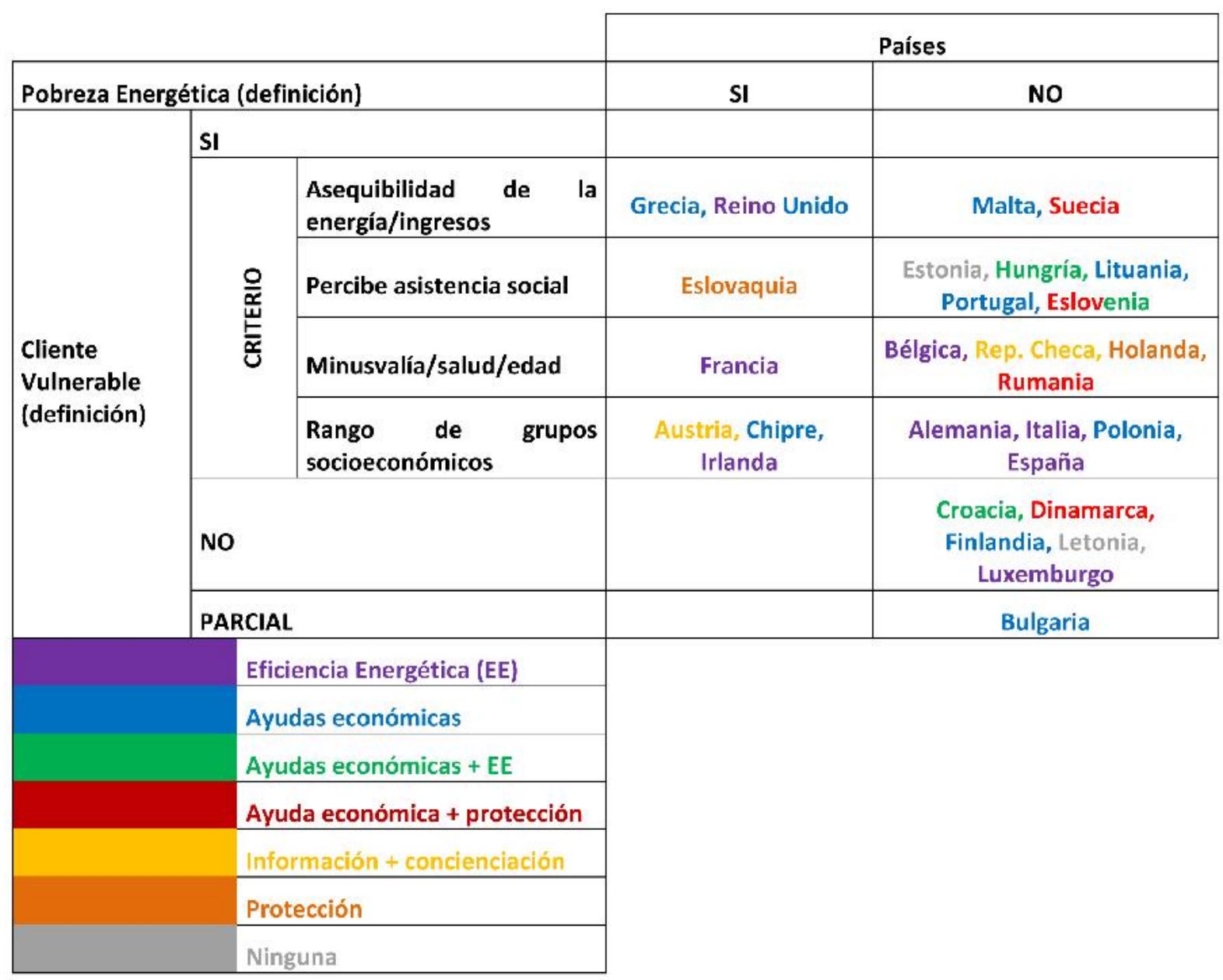

Fuente: elaboración propia a partir de PyE et al. (2015b).

A partir de la definición e identificación de grupos de consumidores surge la necesidad de tomar acciones específicas de protección (a medida de las características de cada Estado). En efecto, existen medidas dirigidas a grupos de personas vulnerables (acciones de mejora de las viviendas, información, facilitación del pago de facturas...). También existen medidas no dirigidas pero que, por su naturaleza, amparan al consumidor vulnerable y al que tiene problemas de pobreza energética.

Gráfico 1. Primeras medidas adoptadas para proteger a los consumidores vulnerables y abordar la pobreza energética (\%) 


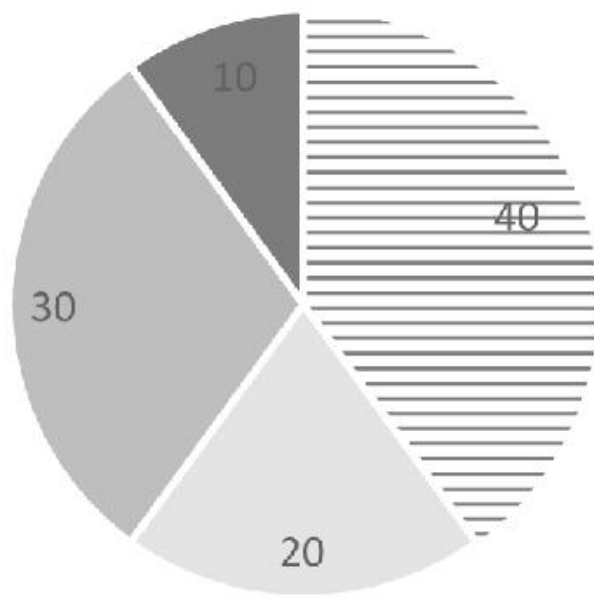

\title{
= Seguridad social
}

Protección ante la desconexión

\author{
Medidas de eficiencia energética
}

- Otros

Fuente: Adaptado de PyE et. al., 2015a, p. 49.

Son medidas aplicadas de forma más general, pero con implicaciones: cómo usar la energía en las viviendas, mejorar el acceso a información sobre tarifas, o a la concesión de ayudas de bienestar o protección ante una posible desconexión. Las principales disposiciones en este ámbito pueden agruparse en cuatro grupos:

- Intervenciones financieras, que difieren entre Estados. Más del 40\% de los Estados miembros utilizan este tipo de intervención como base de ayuda a consumidores vulnerables. Suelen ser gestionadas por el Gobierno central o Administraciones con competencias transferidas. A menudo, la financiación es a través de presupuestos de bienestar social o pagos directos para cubrir el coste energético. Se orientan a aliviar efectos más que a abordar problemas estructurales y su objetivo descansa en el corto plazo. Deben entenderse como escudos de protección transitorios, complementarios a otras medidas de naturaleza estructural como la EE de los hogares.

Gráfico 2. Peso de las medidas relacionadas con la categoría «Intervención financiera» (\%)

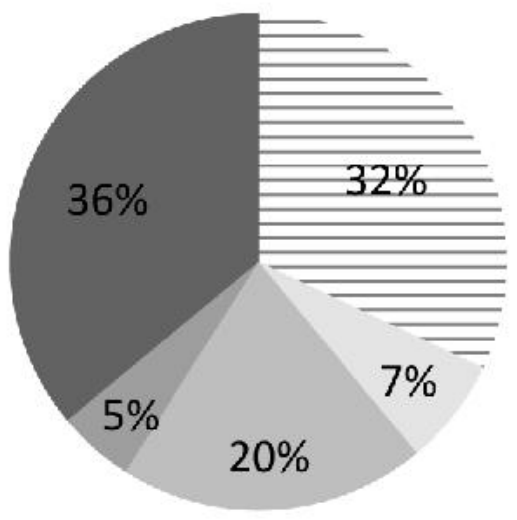

= Pagos/Subsidios coste energético

Pagos (ancianos)/ Subsidios coste energético

Ayudas sociales

Tarifa negociada con empresa eléctrica

Ayuda social (vivienda, costes energía)

Fuente: PyE et al., 2015a, p. 46.

La mayoría de subsidios se adjudican a través de los sistemas de seguridad social y en algunos casos se dirigen en especial a gente mayor (Reino Unido, Dinamarca y Suecia). En algunos países, particularmente, del Sur de Europa (Chipre, España, Francia, Grecia, Portugal y Bélgica) los suministradores de energía ofrecen una tarifa social ${ }^{15}$ ) para que la energía sea un bien asequible. Así, en Bélgica se identifican como clientes vulnerables, todos aquellos hogares en los que algún miembro sea beneficiario de ayudas a la pobreza, tenga discapacidad o una edad avanzada. En Francia, las tarifas sociales se asignan en función de la salud.

- Protección adicional al consumidor. Mientras que las medidas anteriores son fundamentalmente abordadas por el Gobierno central, las de protección al consumidor recaen en el regulador y las compañías energéticas de cara a garantizar que el mercado funciona y no discrimina al cliente vulnerable. Entre estas medidas se encuentran:

- Garantías de desconexión ante impagos (presentes en el 20\% de los Estados).

- Posibilidad de cambiar a otros suministradores aunque se esté endeudado.

- Códigos de conducta para tratar con los consumidores. 
- Identificación, registro e información sobre clientes vulnerables.

- Incentivos para extender las redes a hogares rurales.

- Intervenciones en materia de eficiencia energética. Muchos estudios están mostrando que mejorar la eficiencia energética en los hogares más pobres es una solución sostenible a largo plazo (Atanasiu et al., 2014). Todos los Estados de la Unión cuentan con medidas en este ámbito ${ }^{16)}$, dirigidas a edificios y dispositivos eléctricos, aunque no todas dirigidas a clientes vulnerables o en riesgo de pobreza energética. De hecho, solo el $30 \%$ de los Estados dirigen estas medidas a clientes vulnerables.

- En Reino Unido, se ha cuestionado la eficiencia de estas medidas por no dirigirse bien, por la reducida competencia en la implementación y por poner en manos de grandes compañías energéticas el control total de las mejoras. Algunos autores piensan ${ }^{17)}$ que deberían descentralizarse los programas de eficiencia energética y pasarlos de las compañías de energía a contratistas locales.

Para lograr el éxito de estas medidas, se hace necesaria una valoración «casa a casa», independientemente de los ingresos de los hogares, con el fin de disponer de un conocimiento del parque de inmuebles del país. También se encuentran ayudas gratuitas a hogares pobres en energía y préstamos a bajo o cero interés a otros hogares para proceder a la realización de mejoras en las viviendas.

- Información y concienciación. Ayudan al consumidor a entender sus derechos, informan sobre tarifas de mercado y medidas de ahorro energético. Entre otros se encuentran campañas de concienciación, información sobre facturas y tarifas mediante comparadores de precio y facturación transparente (estas medidas se encuentran más extendidas en países con mercados más liberalizados).

También existen programas de contadores inteligentes, que permiten un mejor conocimiento del uso de la energía por parte del consumidor y seguimiento del consumo por parte del suministrador/regulador, en especial de clientes vulnerables, para facilitar una asistencia focalizada. En Alemania se instalaron para evitar desconectar totalmente a clientes. Así, a quien no podía pagar la factura, se le reducía el límite de consumo a 1.000W en lugar de cortar totalmente el suministro, y ello tras tres avisos.

A nivel comunitario existen numerosas medidas para atajar el problema, un total de 280 , un $40 \%$ de las cuales van dirigidas a clientes vulnerables.

Por su parte, la Política Regional de la UE, referida como Política de Cohesión, es una Estrategia comunitaria que promueve el desarrollo armonioso de los Estados miembros y de sus regiones para evitar las disparidades entre territorios. Esta Política de Cohesión cuenta con tres instrumentos financieros que son: los Fondos Europeos de Desarrollo Regional (ERDF), el Fondo Social Europeo (ESF) y el Fondo de Cohesión ${ }^{18)}$. La UE ha desarrollado proyectos de energías renovables y de eficiencia energética a través de la rehabilitación de edificios aportando Fondos de Cohesión y Fondos Estructurales, que en el período 2007-2013 ascendieron a 10 billones de euros y a 39 entre 2014 y 2020 (ATANASIU et al., 2014).

\section{LA POBREZA ENERGÉTICA EN LA UE}

Tal y como se ha comentado, en 2012 se estimaba que había entre 80 y 124 millones de personas en situación de pobreza energética. Sin embargo, el panorama, lejos de mejorar, parece que va a empeorar, pues se estima que 100 millones de ciudadanos europeos estarán en 2020 en situación de pobreza si se mantienen las medidas actuales (AtANASIU, et al ., 2014). Conviene señalar, que a diferencia de otros territorios, en la UE no existe un problema de acceso a la electricidad y a los servicios energéticos. El problema se encuentra más bien en la capacidad de costear los servicios energéticos. Entre 2007 y 2015, el IPC promedio de la UE ascendió un 13\% y los precios de la electricidad crecieron casi un 22\% en el mismo periodo (EPSU, EAPN, 2017).

En 2012, el 10,8\% de la población europea era incapaz de tener su hogar adecuadamente calentado, porcentaje que ascendía al 24,4\% cuando se hacía referencia a la población con ingresos reducidos. Además, otro $8 \%$ de la población, que no estaba en riesgo de pobreza, también enfrentaba el mismo problema.

Las estadísticas sobre ingresos y condiciones de vida incluyen tres variables que habitualmente se emplean como aproximaciones para valorar la pobreza energética y basándose en el estudio de Thomson, Snell de 2012, Quantifying the prevalence of fuel poverty across the European Union pueden ser empleadas como instrumento para describir y medir la pobreza energética en la UE. Estas variables son: la incapacidad de calentar adecuadamente el hogar, los retrasos en los pagos de las facturas energéticas y la presencia de fugas en el techo, paredes húmedas, pisos o cimientos, o podredumbre en marcos de ventanas o en el suelo.

Tabla 2. Evolución de los principales parámetros que miden la pobreza energética en la UE. Evolución 


\begin{tabular}{|c|c|c|c|c|c|c|c|c|c|}
\hline & \multicolumn{3}{|c|}{$\begin{array}{l}\text { Retrasos en el } \\
\text { pago de facturas }\end{array}$} & \multicolumn{3}{|c|}{$\begin{array}{c}\text { Población en } \\
\text { viviendas con } \\
\text { problemas }\end{array}$} & \multicolumn{3}{|c|}{$\begin{array}{l}\text { Incapacidad de } \\
\text { mantener la } \\
\text { vivienda }\end{array}$} \\
\hline & 2005 & 2010 & 2015 & 2005 & 2010 & 2015 & 2005 & 2010 & 2015 \\
\hline UE28 & & 9,1 & 9,1 & & 16 & 15 & & & 9,4 \\
\hline Bélgica & 5,7 & 5,8 & 5,1 & 15 & 19 & 18 & 14,1 & 5,6 & 5,2 \\
\hline Bulgaria & 19,0 & 31,6 & 31,4 & 31 & 15 & 13 & 69 & 66,5 & 39,2 \\
\hline República Checa & 7,2 & 4,2 & 3,0 & 21 & 12 & 9 & 9,3 & 5,2 & 5,0 \\
\hline Dinamarca & 2,8 & 3,2 & 3,4 & 8 & 8 & 16 & 8,9 & 1,9 & 3,6 \\
\hline \begin{tabular}{|l|} 
Alemania \\
\end{tabular} & 2,8 & 3,5 & 4,0 & 14 & 13 & 13 & 4,6 & 5,0 & 4,1 \\
\hline Estonia & 10,3 & 11,0 & 7,9 & 25 & 19 & 13 & 2,6 & 3,1 & 2,0 \\
\hline \begin{tabular}{|l|l|} 
Irlanda \\
\end{tabular} & 6,9 & 12,6 & 15,1 & 12 & 13 & 14 & 4,0 & 6,8 & 9,0 \\
\hline Grecia & 26,5 & 18,8 & 42,0 & 21 & 17 & 15 & 15,7 & 15,4 & 29,2 \\
\hline España & 4,5 & 7,5 & 8,8 & 18 & 22 & 15 & 9,4 & 7,5 & 10,6 \\
\hline Francia & 7,2 & 7,1 & 5,9 & 12 & 13 & 13 & 5,3 & 5,7 & 5,5 \\
\hline Croacia & & 28,0 & 28,7 & & 20 & 11 & & 8,3 & 9,9 \\
\hline Italia & 10,5 & 11,2 & 12,6 & 23 & 21 & 24 & $-11,0$ & 111,6 & 17,0 \\
\hline Chipre & 9,7 & 16,3 & 20,1 & 36 & 30 & 27 & 33,7 & 27,3 & 28,3 \\
\hline Letonia & 18,9 & 22,5 & 16,7 & 40 & 25 & 24 & 29,8 & \begin{tabular}{|l|}
19,1 \\
\end{tabular} & 14,5 \\
\hline Lithuania & 20,7 & 10,9 & 8,4 & 32 & 19 & 17 & \begin{tabular}{|l|}
34,8 \\
\end{tabular} & \begin{tabular}{|l|}
25,2 \\
\end{tabular} & 31,1 \\
\hline \begin{tabular}{|l} 
Luxemburgo \\
\end{tabular} & 3,2 & 2,1 & 2,4 & 15 & 17 & 14 & 0,9 & 0,5 & 0,9 \\
\hline \begin{tabular}{|l|} 
Hungria \\
\end{tabular} & 15,9 & 22,1 & 19,4 & 33 & 24 & 25 & 17,7 & \begin{tabular}{|l|}
10,7 \\
\end{tabular} & 9,6 \\
\hline Malta & 7,9 & 6,8 & 10,2 & 8 & 12 & 10 & 12,6 & 14,3 & 13,9 \\
\hline \begin{tabular}{|l|} 
Paises Bajos \\
\end{tabular} & 3,2 & 2,1 & 2,7 & 18 & 15 & 16 & 3,1 & \begin{tabular}{|l|} 
\\
\end{tabular} & 2,9 \\
\hline Austria & 1,9 & 4,4 & 3,5 & 10 & 15 & 12 & 3,2 & 3,8 & 2,6 \\
\hline \begin{tabular}{|l} 
Polonia \\
\end{tabular} & 24,2 & 13,9 & 9,2 & 44 & 16 & 12 & 33,6 & 14,8 & 7,5 \\
\hline Portugal & 5,0 & 6,4 & 7,8 & 19 & 22 & 28 & 40,0 & 30,1 & 23,8 \\
\hline Rumania & & 26,5 & 17,4 & & 19 & 13 & & 20,1 & $\overline{13,1}$ \\
\hline Eslovenia & 12,6 & 18,0 & 17,5 & 19 & 32 & 27 & 2,6 & 4,7 & 5,6 \\
\hline Eslovaquia & 8,3 & 9,6 & 5,7 & 7 & 6 & 6 & 13,6 & 4,4 & 5,8 \\
\hline \begin{tabular}{|l|} 
Finlandia \\
\end{tabular} & 7,4 & 6,9 & 7,5 & 5 & 5 & 4 & 2,6 & 1,4 & 1,7 \\
\hline Suecia & 5,0 & 4,3 & 2,7 & 6 & 8 & 8 & 1,4 & 1,7 & 0,9 \\
\hline Reino Unido & 5,4 & 5,6 & 7,0 & 15 & 15 & 15 & 5,7 & 6,1 & 7,8 \\
\hline Islandia & 7,3 & 7,0 & 6,6 & 19 & 16 & 19 & 9,3 & 1,4 & 1,4 \\
\hline Noruega & 7,9 & 6,3 & 3,2 & 8 & 8 & 7 & 1,3 & 0,7 & 0,5 \\
\hline \begin{tabular}{|l|} 
Suiza \\
\end{tabular} & & 4,8 & 3,6 & & 9 & 12 & & 7,3 & 0,6 \\
\hline $\begin{array}{l}\text { Antigua República } \\
\text { Yugoslava de } \\
\text { Macedonia }\end{array}$ & & 39,3 & 40,1 & & 25 & 12 & & 28,8 & 23.4 \\
\hline Serbia & & & 34,8 & & & 23 & & & 15,2 \\
\hline
\end{tabular}

Fuente: elaboración propia a partir de EU-SILC Survey en Eurostat.

La evolución de estos parámetros ha sido diferente en cada país. En todo caso, parece que existen tres grandes grupos de países. Por un lado, los de Europa del Este, con elevadas tasas de pobreza energética, lo que se observa por una combinación de valores elevados para todos los parámetros. Por otro lado, están los países del Mediterráneo, como España y Grecia, que con un parque de viviendas poco eficiente, muestran tasas diferentes 
de capacidad de mantener las viviendas calientes. Por último, se encuentran el resto de países de la UE, con unos mejores valores de todas estas variables.

Los datos muestran que se ha producido una mejora del estado de las viviendas con problemas de EE de los países de la UE-28, entre 2005 y 2015. No obstante, y debido a la crisis, la capacidad para hacer frente a las facturas energéticas ha empeorado. Además, salvo algunos casos más concretos como Grecia, Italia o Irlanda, ha mejorado la capacidad de mantener caliente la vivienda. Esto se representa de manera visual en los siguientes gráficos.

Gráfico 3. Evolución de los principales parámetros que miden la pobreza energética en la UE (2005 y 2015)

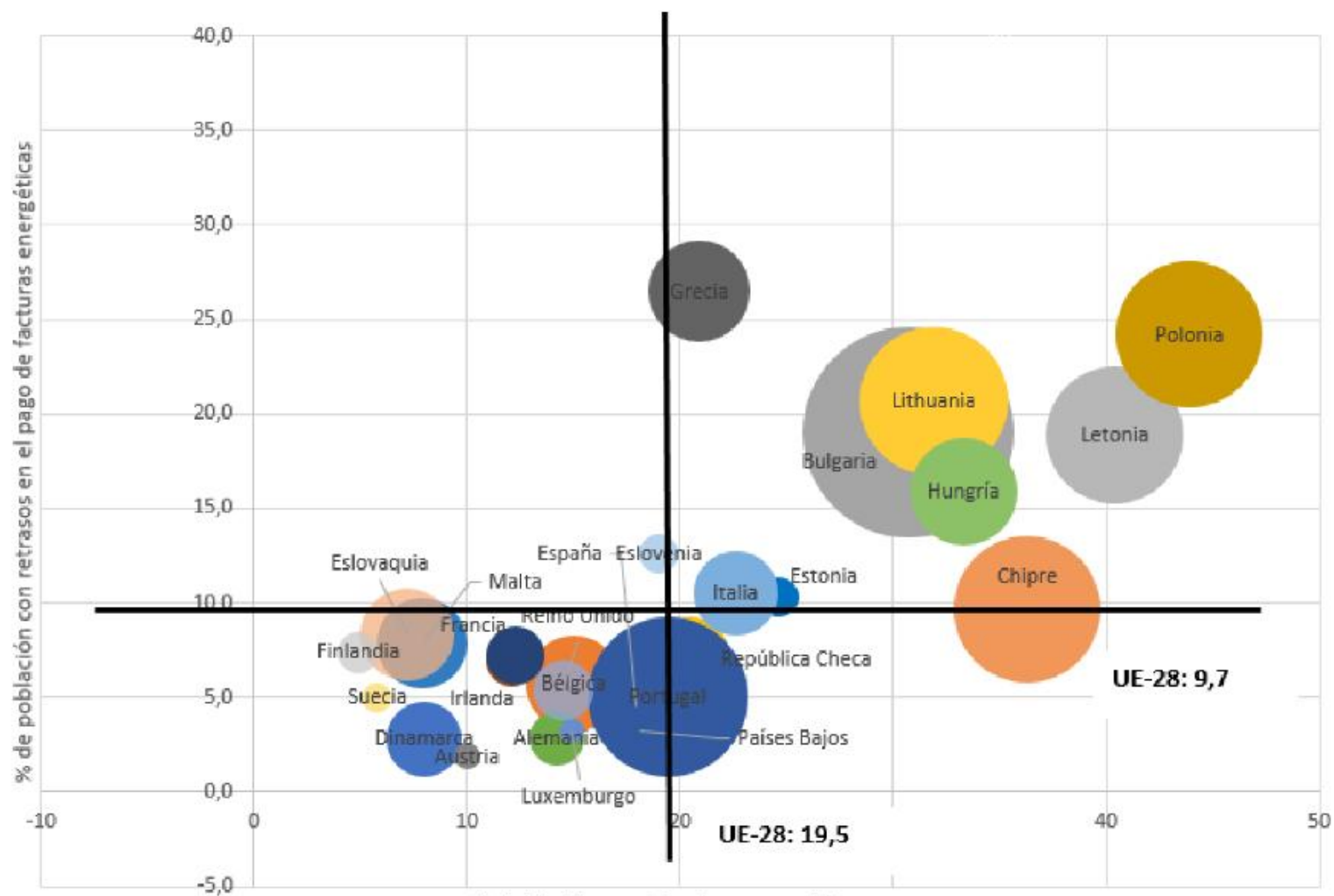

$\%$ Poblaciön en viviendas con problemas 


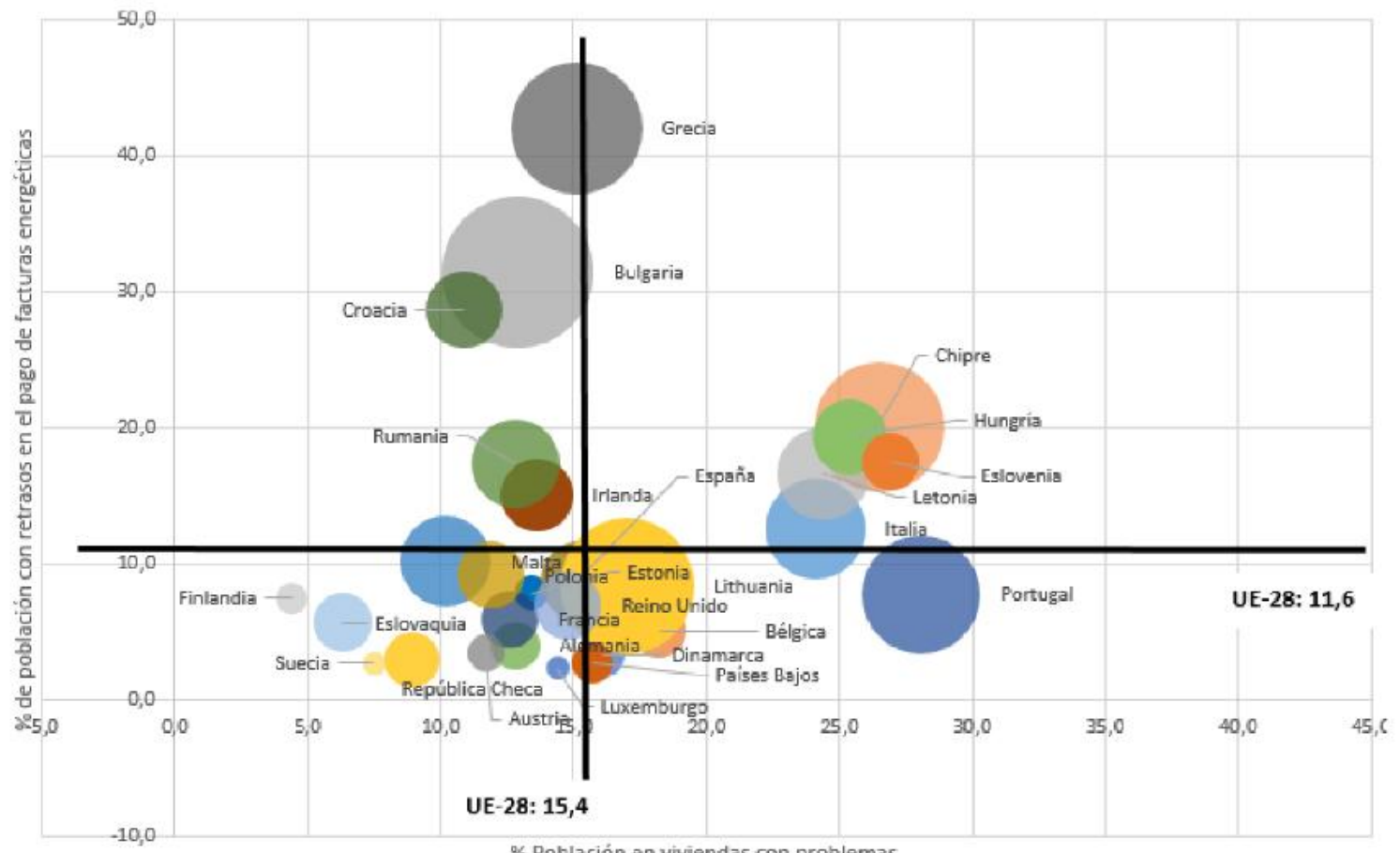

\% Población en viviendas con problemas

Nota 1: el tamaño de las burbujas representa la incapacidad de mantener caliente la vivienda.

Nota 2: el gráfico de 2005 no presenta datos para Rumania ni para Croacia.

Fuente: elaboración propia a partir de EU-SILC Survey en Eurostat.

III. REINO UNIDO: LÍDER EN LA CONCEPTUALIZACIÓN Y LA LUCHA CONTRA LA POBREZA ENERGÉTICA

El término de pobreza energética se ha empleado en el Reino Unido desde mediados de los años 70. En sus inicios servía para describir cualquier manifestación de incapacidad para cubrir los costes energéticos, sin una definición oficial del problema. Entre los principales síntomas se encontraban: una deuda con un suministrador de energía, desconexión de la red o riesgo de esta ${ }^{19)}$, prepago de energía, condiciones insanas en los hogares, enfermedades y mortalidad asociadas al frío, síndrome de calentar o comer (EPEE, 2006).

Una definición más adecuada de pobreza energética tenía que incluir más que la incapacidad de pagar las facturas. Por ello, en un primer intento de definir de manera objetiva la pobreza energética, se acudió a una proporción del gasto razonable de los ingresos de un hogar en energía. La primera estimación se llevó a cabo en 1988 y supuso el escrutinio del 30\% de los hogares más pobres. En dicho análisis se observó que este 30\% de la población gastaba más de un 10\% de sus ingresos en energía (EPEE, 2006). Esta definición e indicador del 10\% fueron legitimados en 1998 aunque no fue hasta 2000, con la Warm Homes and Energy Conservation Act , cuando se definió formalmente la pobreza energética en la legislación del Reino Unido (Кон et al., 2012).

Ya en 2001, se publicó la primera estrategia contra la pobreza energética en el Reino Unido (RU), resultado de la Warm Homes and Energy Conservation Act . Para ello, se empleó como criterio el indicador anterior del 10\% (HM GovernMENT, 2015).

1. DOS INDICADORES, CUATRO NACIONES

La definición actual de pobreza energética en el Reino Unido, no es coincidente en las cuatro naciones que la integran (Inglaterra, Escocia, Gales e Irlanda del Norte).

En la actualidad, en Gales, Escocia e Irlanda del Note, se calcula la pobreza energética en base al indicador del 10\%. Bajo este indicador, un hogar sufre pobreza energética si requiere gastar más del 10\% de sus ingresos en combustible para calentar el hogar (DECC, 2013 en Dubois y Meier, $2014 \mathrm{~b})$, lo que sería $21^{\circ} \mathrm{C}$ en el área habitada principal y $18^{\circ} \mathrm{C}$ en el resto de habitaciones (NEA, 2016). El ratio se expresa como sigue:

\section{Pobreza energética $=\frac{\text { Costes modelados del combustible (ie.Consumo modelado } x \text { precio) }}{\text { Ingresos }}$}

En estos territorios se reconoce otro indicador del 20\%, que consiste en aquellos hogares que gastan más del 20\% de sus ingresos en energía y se encuentran en pobreza energética extrema (House OF Commons LiBRARY, 2017).

El indicador del 10\% es a priori simple, fácil de comunicar y relativamente versátil. Sin embargo, adolece de importantes desventajas que han sido ampliamente puestas de manifiesto en la literatura. Las críticas son fundamentalmente debidas, por un lado, a su excesiva sensibilidad a los precios de la energía, infraestimando la escala del problema cuando los precios son bajos y sobreestimándola cuando son altos (Economics for ENERGY, 2015).

El problema de aplicar esta definición de pobreza energética, es que este criterio ignora a aquellas personas que podrían alcanzar el umbral para ser considerados pobres energéticos si calentaran adecuadamente sus hogares, pero que en realidad gastan menos y consecuentemente tienen un 
hogar frío (EPSU, EAPN, 2017). Además, este indicador del 10\% puede incluir un número significativo de hogares que no son pobres energéticos, como hogares de renta alta con viviendas ineficientes. Así mismo, solo reflejaría la coyuntura de Reino Unido (RU) a finales de los años 80 y, en particular, la desigualdad y no tanto la pobreza (ECONOMICS FOR ENERGY, 2015).

En vista de lo anterior, en 2012, el profesor Hills recomendó un nuevo método de cálculo ${ }^{20)}$, mediante el Low Income High Costs (LIHC), que se emplea en Inglaterra ${ }^{21)}$ desde 2011 (recogido en las estadísticas de Inglaterra publicadas a partir de 2013). Este nuevo parámetro convierte en equivalentes los factores de ingresos y gastos en combustible, así como la deducción de los costes de los ingresos. Se trata de un indicador relativo, frente al del $10 \%$ que es de naturaleza absoluta.

Según este planteamiento, se considera pobre en energía al hogar que presenta costes energéticos por encima de la media nacional y que, si hiciese frente a este gasto, le quedaría un ingreso residual que le situaría por debajo del umbral de pobreza oficial.

De esta manera, un hogar se considera en situación de pobreza energética en Inglaterra si sus ingresos se encuentran por debajo de la línea de pobreza (tomando en consideración costes de energía) y sus costes en energía son superiores a lo que es habitual para ese tipo de hogar (DECC 2013 en Pye et al., 2015a).

El empleo de este indicador exige definir ambos umbrales. Con respecto al primero, la aproximación de Hills es la del $60 \%$ de la mediana equivalente de ingresos después de restar los gastos de la vivienda y los gastos energéticos equivalentes. Para el segundo umbral, Hills aplicó la mediana del gasto en energía calculado sobre el total de hogares (ECONOMICS FOR ENERGY, 2015).

Este indicador mide no solo la extensión del problema (cuántos hogares en pobreza energética existen) sino también la profundidad del mismo (en qué grado les afecta esta pobreza energética). Esto último se mide a través del conocido como fuel poverty gap, que mide cuánta más energía gasta un hogar en pobreza energética en mantener cálida la vivienda frente a un hogar típico.

Para estimar el indicador LIHC, se modelizan los ingresos de un hogar, calculando la diferencia entre los ingresos y los costes de la vivienda (hipoteca o alquiler), en la medida en que el dinero gastado en la vivienda no se puede dedicar a la compra de combustible. Una vez estimada esta diferencia, los ingresos se ajustan para reflejar que los diferentes tipos de hogares tienen diferentes necesidades de gastos ${ }^{22}$. A este proceso se le denomina «equivalisation».

A diferencia del indicador del $10 \%$, se trata de un indicador excesivamente complejo y no transparente, como consecuencia de la necesidad de modelizar los gastos energéticos equivalentes. Además, al definir el umbral del gasto energético, el indicador obvia el efecto de la EE de los hogares, y dificulta que recoja a aquellos hogares que podrían salir de la pobreza energética mediante una reducción de sus gastos energéticos.

Según se opte por el 10\% o por LIHC, se obtienen diferentes resultados en la clasificación de los hogares. Así, en 2012-13 se reconoció que, aplicando el indicador de 10\%, los valores de pobreza energética se incrementaban. Si se tomaran como ejemplo los datos de 2009 , Inglaterra tendría 3,9 millones de hogares en situación de pobreza energética aplicando el indicador del 10\%, mientras que si se aplicaba el indicador LIHC, el número de hogares en esta situación bajaría a 2,6 millones (NEA, 2016) ${ }^{23)}$.

Hay autores que consideran positiva la aportación realizada con la introducción de este nuevo indicador, sin embargo, opinan que existe campo de mejora, en la medida en que se ha olvidado incluir el elemento subjetivo del agente que sufre pobreza energética y su experiencia, para llegar a entender la extensión y profundidad del problema en el RU (Кон et al., 2012).

En todo caso, ambas definiciones incluyen los requerimientos energéticos para calefacción, agua caliente sanitaria, iluminación, equipamientos eléctricos u otros y cocina. Estos requisitos se modelizan en base a una serie de factores como las circunstancias económicas de los hogares, el tipo de sistema de calefacción empleado y combustible necesario y las características de las viviendas.

Las diferentes definiciones e incluso matices existentes entre naciones, se deben a que la pobreza energética es una competencia transferida parcialmente, por lo que cada Administración tiene objetivos de política individuales, medidas diferentes y resultados distintos. Así, cada Administración tiene potestad para influir en determinados aspectos de las políticas de pobreza energética (por ejemplo, en los programas de eficiencia energética), pero no en otros (como los ingresos y las condiciones de mercado que influyen en los precios de los combustibles) (DECC, 2016).

\section{LA ENERGÍA EN EL REINO UNIDO: SUMINISTRO, PRECIOS, CONSUMO DOMÉSTICO Y FACTURA ENERGÉTICA}

En los años 80, cuando se inició el proceso de privatización del sector energético, había 14 compañías eléctricas en el RU, privatizadas en 1989 a través de la Electricity Act , que suministraban en un ámbito regional, y una única empresa que suministraba gas (British Gas), que fue privatizada en 1986 mediante la Gas Act . En 2017, existen 48 suministradores de gas y electricidad en el país (DELABARRE y Hough, 2017).

No obstante, existen seis compañías, conocidas como las «big six» (Centrica plc, EDF Energy, E.ON, SSE, Scottish Power y Npower), integradas verticalmente para suministrar gas y electricidad que abastecen alrededor del $85 \%$ de la electricidad y del $84 \%$ del gas domésticos. Estas cifras son inferiores al 95\% de la energía de uso doméstico que suministraban en 2012.

En Gran Bretaña, alrededor del 70\% de los consumidores domésticos de las seis mayores compañías energéticas pagan por una tarifa variable, estándar y cara. Estos consumidores, se estima que podrían ahorrar anualmente 300 libras (£) cambiando de suministrador. Es decir, los consumidores podrían estar pagando 1,4 billones de libras más de lo que pagarían en un mercado competitivo (DELEBARREyHough, 2017).

No obstante, y a pesar de los anuncios de nuevos aumentos de los precios de la energía, estudios recientes han puesto de manifiesto que no ha habido prácticas colusorias en los mercados, mayorista ni minorista, aunque la competencia no está funcionando como se esperaba (DelebarreyHough, 2017).

Los precios de la electricidad aumentaron un 61\% entre 2004 y 2016. De este aumento alrededor de la mitad se debió al incremento de los costes del mercado mayorista y de las redes, 25 puntos porcentuales al impacto de políticas climáticas y siete puntos porcentuales a otras políticas (Committee on Climate Change, 2017). Estos precios para los consumidores residenciales en el RU están por debajo de los de los países de la UE-15, siendo superiores en Alemania y Dinamarca, y menores en Holanda y Finlandia.

Los precios del gas, por su parte, aumentaron un 98\% en el mismo período, donde 84 puntos se debieron al coste del mercado mayorista y las redes, tres puntos a las políticas de cambio climático y 11 puntos a otras políticas. En este caso, los precios son los terceros menores de la UE-15, ligeramente superiores a los de Bélgica y un 18\% mayores que Luxemburgo. Los mayores precios se encuentran en Suecia (104\% por encima de los del RU).

Gráfico 4. Precio de la electricidad para un consumidor doméstico con un consumo anual de entre 2.500 y 5.000 kWh, impuestos y tasas incluidas 


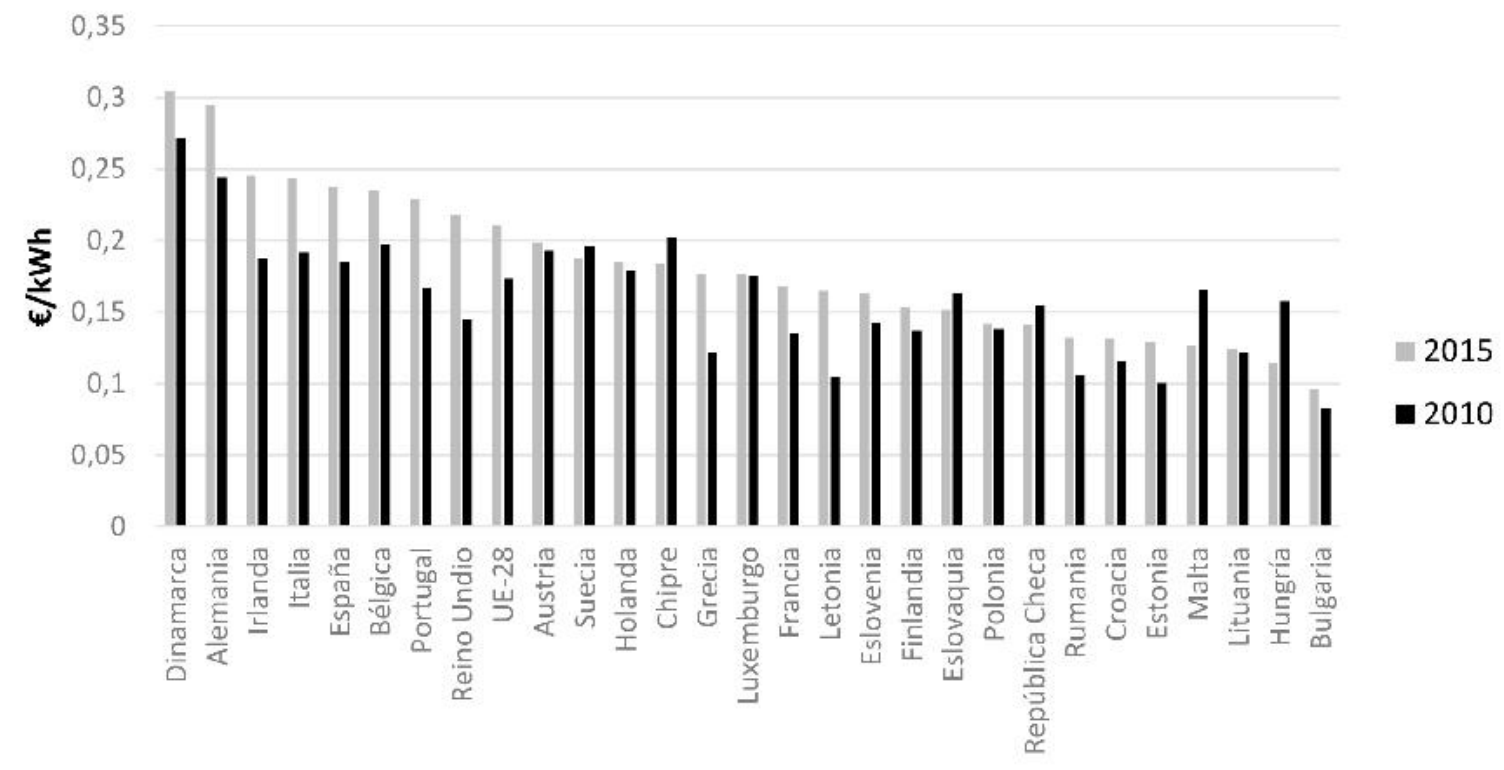

Fuente: elaboración propia a partir de Eurostat.

Gráfico 5. Precio del gas para un consumidor doméstico con un consumo anual de entre 20 y 200 GJ, impuestos y tasas incluidas

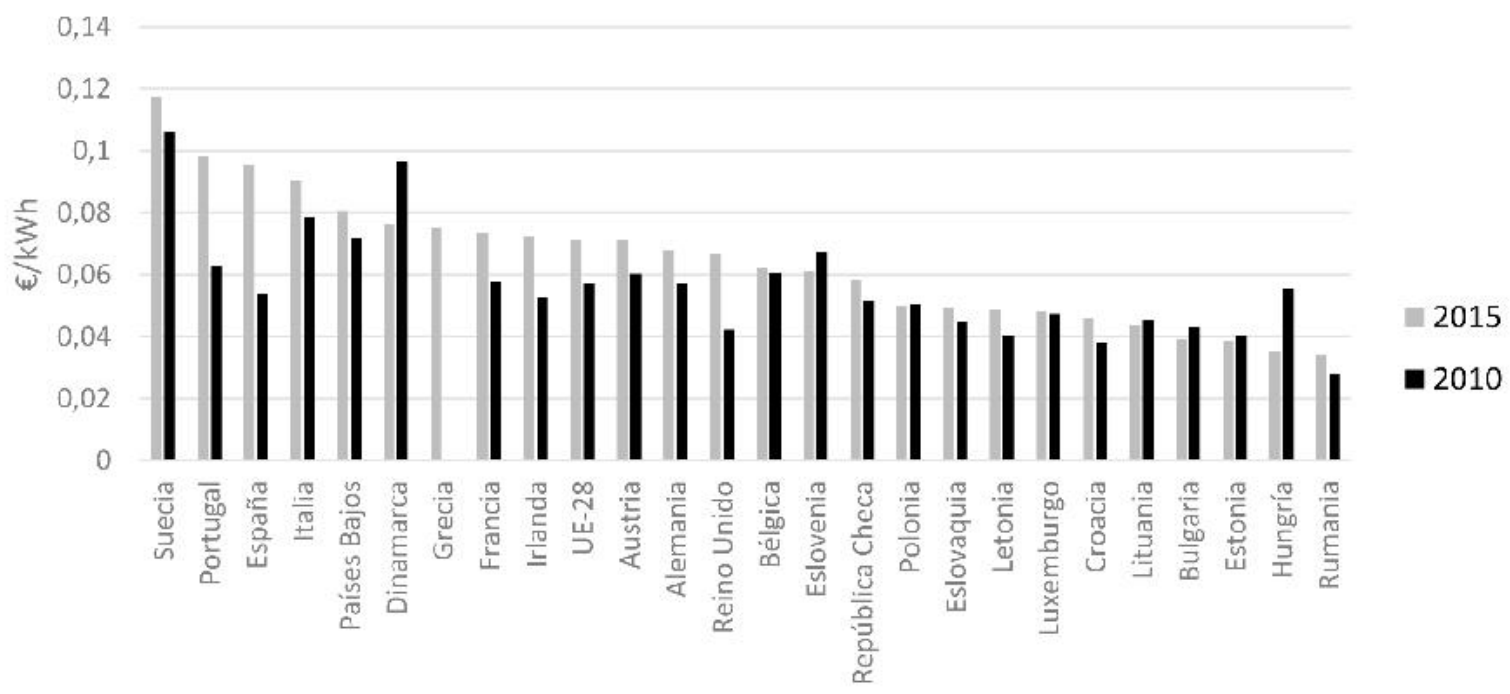

Fuente: elaboración propia a partir de Eurostat.

Esta tendencia al alza de los precios energéticos llevó a un aumento de las cifras de pobreza energética hasta 2013, como consecuencia de la gran sensibilidad del indicador del 10\% a los valores promedio (House of Commons Library, 2017).

Ante esta situación, es necesario establecer medidas de salvaguarda para proteger, entre otros, a los consumidores que disponen de contadores de prepago ${ }^{24)}$, cuyas posibilidades son limitadas y que podrían reducir sus facturas alrededor de 300 millones de libras al año (DELEBARRE y Hough, 2017). Además, se hace necesario favorecer las páginas web de comparaciones de precios entre compañías y la disponibilidad de información, que debería ser más clara. En este sentido los contadores inteligentes pueden jugar un papel relevante en el futuro.

En RU, el 85\% de los hogares consume gas (en calefacción y agua caliente sanitaria) y electricidad (iluminación y electrodomésticos) (CommitTEE oN Climate Change, 2017). Un hogar medio consume $13.500 \mathrm{kWh}$ de gas al año y $3.550 \mathrm{kWh}$ de electricidad. A pesar de que ha aumentado el número de equipamiento doméstico eléctrico, el consumo energético ha caído, lo que demuestra la mejora de la eficiencia energética.

Si bien, incluso con un mismo nivel de consumo energético, las facturas pueden variar de manera considerable, tal y como se ha señalado, en función del suministrador, la tarifa y el medio de pago. En 2016, un consumidor doméstico promedio pagaba una factura conjunta de unas $1.160 £$ ( $615 £$ de gas y $545 £$ de electricidad). Con un aumento de la factura energética entre 2004 y 2016 del $278 \%$ en términos reales, la mayor parte de esta reflejaba los costes del mercado y de las redes. Alrededor de 105£, en 2016, estaban relacionadas con el apoyo al desarrollo de una electricidad baja en carbono y a la eficiencia energética.

Como consecuencia del objetivo establecido a 2030, de lograr que el 75\% de la generación eléctrica provenga de fuentes bajas en carbono, se espera que la factura energética aumente anualmente entre 85 y $120 £$ (95£ como promedio). Si se suma esta cantidad a los aumentos anteriores, 
supondría que las políticas en favor de una economía baja en carbono costarían entre 190 y $225 £$ al año en 2030 (CommitTeE on CLimate Change, 2017). Este sobre coste podría compensarse a través de medidas de mejora de la eficiencia energética, lo que supondría ahorros de aproximadamente $150 £$. No obstante, otros factores como los precios de los mercados mayoristas y su evolución, podrían añadir unas $200 £$ a la factura al año hacia 2030.

Alrededor del 6\% de los hogares del RU emplean electricidad como principal fuente de calor. Generalmente son propiedades más pequeñas y por ende, tienen menores facturas energéticas y un menor nivel de consumo. Sin embargo, afrontan una elevada cuota de costes de políticas de reducción de emisiones. Alrededor del $4 \%$ de los hogares emplean derivados del petróleo para calentar. Generalmente es más caro que el gas y las facturas están sometidas a una mayor incertidumbre debido a la fluctuación de los precios mundiales del crudo.

\section{LA POBREZA ENERGÉTICA EN EL REINO UNIDO: CUATRO NACIONES CUATRO PLANTEAMIENTOS}

En 2001, el Gobierno británico y las Administraciones con competencia en este ámbito establecieron una estrategia para erradicar la pobreza energética. En 2003, se fijó como objetivo el año 2010 para terminar con los hogares vulnerables. Sin embargo, a pesar de las políticas introducidas para este fin, en 2010-11 se reconoció que el objetivo era inalcanzable sin la aplicación de cambios importantes. La Estrategia estaba en crisis y la inversión del Gobierno en programas clave se estaba reduciendo. Asimismo, existían importantes incertidumbres para terminar con esta situación.

Además, en el periodo comprendido entre 2003 y 2013, la pobreza energética aumentó en el Reino Unido, en base al estimador del 10\%, pasando de alrededor de 1,7 millones de hogares a 4,5 millones. 2009 marcó un máximo previo al de 2013. Además, desde 2010 la evolución de la pobreza energética ha vuelto a seguir una tendencia creciente.

En base a datos de 2016, se estima que, a pesar de los avances, 4,5 millones de hogares sufren pobreza energética en el Reino Unido, es decir, el $17 \%$ de los hogares británicos (NEA, 2016). Como puede observarse en términos totales Inglaterra tiene el mayor número de hogares en pobreza energética, aunque en términos relativos es menor su incidencia.

Tabla 3. Pobreza energética en RU

\begin{tabular}{|l|l|l|l|l|l|}
\hline & $\begin{array}{c}\text { Población en millones } \\
\text { (2015) }\end{array}$ & Extensión (miles km²) & $\begin{array}{c}\text { Número de hogares en } \\
\text { pobreza energética (LIHC) }\end{array}$ & $\begin{array}{c}\text { Número de hogares en } \\
\text { pobreza energética (10\%) }\end{array}$ \\
\hline Inglaterra (2015) & 53 & 130 & 2.500 .000 & $11 \%$ & \\
\hline Escocia (2015) & 5,35 & 78 & & 748.000 \\
\hline Gales (2016) & 3 & 20,7 & & 291.000 \\
\hline Irlanda del Norte (2011) & 1,85 & 14,1 & & 294.000 \\
\hline
\end{tabular}

Nota: se estima en un 11,6\% los hogares en pobreza energética en Inglaterra en función del criterio del 10\%.

Fuente: elaboración propia a partir de Committee on Climate Change (2017), Office of National Statistics (2017).

Existen diferentes medidas para la lucha contra la pobreza energética en el Reino Unido. De ellas, algunas se centran en la pobreza energética como una faceta de la pobreza en general y consisten en medidas de apoyo a la renta ( Winter Fuel Payment ${ }^{25)}$, Cold Weather Payment 26)). Otras medidas permiten reducir la carga de la factura energética a través de un apoyo directo a los grupos de hogares con menores niveles de renta ( Warm Home Discount ).

Existen también programas relacionados con la eficiencia energética, que no siempre logran aplicarse a los hogares más vulnerables. Entre ellos se encuentra el Warm front Scheme, que consiste en subvenciones públicas para la mejora de la calefacción (cambio de calderas) y el aislamiento de los hogares que se encuentran recibiendo algún tipo de ayuda pública y que viven en propiedades mal aisladas o que no disponen de un sistema de calefacción central.

Por otro lado, en el ámbito de la EE, si bien el Green Deal fue la principal propuesta de Gran Bretaña para la mejora de la eficiencia energética, en la actualidad, la principal política para luchar contra la pobreza energética es la Energy Company Obligation (ECO), un esquema que provee de fondos para medidas de eficiencia energética en aquellos hogares más necesitados. La primera fase se inició en 2013. En la actualidad se va a prorrogar el esquema hasta septiembre de 2018, ampliando la aportación al Affordable Warmth Obligation frente al Carbon Saving Communities Obligation .

Los fondos aportados por el programa ECO se han reducido los últimos años, lo que se considera inadecuado para lograr los objetivos establecidos de mejorar la eficiencia de las viviendas, que deben pasar a un nivel C en 2030. Para ello, se estima que sería necesario invertir 1,2 billones de libras al año (Committee on Climate Change, 2017).

A continuación, se va a presentar la situación en cada una de las naciones que conforman el RU.

\subsection{Irlanda del Norte}

En Irlanda del Norte, la última encuesta que recoge la situación referente a la pobreza energética ( Housing Condition Survey for Northern Ireland) fue de 2011, donde se consideraba que un hogar se encontraba en situación de pobreza energética si, para mantener un nivel de temperatura aceptable en todo el hogar, los ocupantes tenían que gastar más del 10\% de sus ingresos en la adquisición de combustible (DSDNI 2011).

Se introdujo también un indicador de severidad según el cual, los hogares que gastan más de un 15\% de sus ingresos en energía están en pobreza energética severa y si gastan el 20\% o más se encuentran en pobreza energética extrema (Department for Social DEvelopment, 2011).

En aquel momento, las cifras indicaban que el 42\% de los hogares norirlandeses sufrían este mal, es decir, 294.000 hogares. Es más, en general, la proporción de ingresos del hogar que debían dedicarse a pagar la energía era mayor aquí que en otros lugares del RU. En 2009, las estadísticas indicaban que en Irlanda del Norte había un 22\% de los hogares en pobreza energética, un 11\% en severa y otro 11\% en extrema. Además, se identificó que en este territorio la edad juega un papel decisivo, dado que en los grupos de población de 60-74 años el 53\% está en pobreza energética y en aquellos grupos de más de 75 años la cifra alcanza el 76\% (DEPARTMENT For Social DeVELOPMENT, 2011).

A pesar de estos datos, en Irlanda del Norte el Gobierno no ha establecido una obligación de reducción de la pobreza energética y, por ello, no cuenta con un objetivo en esta materia. Tampoco ha desarrollado una hoja de ruta que marque cómo y cuándo se va a erradicar la pobreza energética. En todo caso, en 2011, se desarrolló la estrategia sobre pobreza energética Warmer Healthier Homes que considera necesarias la mejora de la eficiencia energética y el acceso a una energía asequible.

Los principales problemas a los que se enfrentan los hogares en esta nación se basan en que el 68\% de estos dependen del petróleo para la calefacción (Committee on CLImATe Change, 2017), cuyos precios sufren grandes fluctuaciones ${ }^{27}$. Además, la mayoría de los hogares no cuentan con una infraestructura de almacenamiento del combustible adecuada. Existen iniciativas voluntarias por comunidades, que cuentan con el apoyo de las instituciones locales, la Public Health Agency y Northern Ireland Housing Executive with Bryson Energy, aunque no llegan a toda la población. 
Otra dificultad relacionada con la anterior es que el fueloil de calefacción no ofrece el soporte a los estándares de eficiencia energética que ofrece el gas, lo que tiene como resultado instalaciones deficientes y con altos costes de mantenimiento. De igual manera, Irlanda del Norte se enfrenta a mayores precios de la energía (House of Commons Library, 2017). Además, apenas existen tres/cuatro suministradores de fuelóleo de calefacción y no existía casi competencia ni en electricidad ni en gas hasta 2010 (Austin, 2016).

A todo lo anterior, se le añade que los hogares norirlandeses tienen menores ingresos que el resto de naciones (CommitTEe ON CLIMATE CHANGE, 2017) y que tras un análisis preliminar de las condiciones de las viviendas en Irlanda del Norte, se observa que se han producido pocos cambios respecto a la situación del informe presentado en 2011 en cuanto a tipo de viviendas, antigüedad de las mismas, régimen de propiedad ${ }^{28)}$, mantenimiento, etc. (NIHE's RESEARCH Unit, 2017), con lo que todo ello puede suponer en temas de eficiencia energética.

El mecanismo clave en la lucha contra la pobreza energética en Irlanda del Norte es el Affordable Warmth Scheme , que lleva en funcionamiento desde 2014/2015 y se estima que mejora la eficiencia energética de 5.000 hogares en pobreza energética al año, cifra inferior a los 9.000 hogares que abarcaba el programa anterior Warm Homes Scheme. Ello se debe a que se centra en hogares con ingresos por debajo de las $20.000 £$ y a que emplea un enfoque de vivienda amplio, que incluye el aislamiento, la mejora de la calefacción y la instalación de doble acristalamiento. Se estima que se necesitaría hasta 2025 para cubrir a los 33.000 hogares en pobreza energética extrema (NEA, 2017). Este programa tiene en cuenta como criterio de cualificación no solo la recepción de ayudas de la Seguridad Social, sino también el nivel de ingresos.

También está el Northern Ireland Sustainable Energy Programme (NISEP), cuya política sobre pobreza energética se basaba en la estrategia Warmer Healthier Homes, de 2011. El NISEP, que llegó al final de su vida el 31 de marzo de 2017, sigue en vigor por no haber un programa que lo sustituya (NEA, 2017). En principio, se había propuesto el "Energywise" como esquema de mejora de la eficiencia energética, habiendo sido sometido a consulta en 2016. Incluía la concesión de ayudas y préstamos así como otras mejoras respecto al NISEP (DEPARTMENT OF THE Economy, 2016). Por el momento, no se tiene constancia de que haya sido aprobado.

En todo caso, lo que sí parece que es fundamental es que la salud juegue un papel central en el nuevo programa gubernamental 2016-2021, lo que requiere un alineamiento con la acción propuesta para una nueva estrategia de pobreza energética (NEA, 2017).

3.2. Gales

En Gales, como se ha señalado, la pobreza energética se define como tener que gastar más del 10\% de los ingresos del hogar en combustible para mantener un nivel de confort satisfactorio (PYE et al., 2015a). Si los hogares emplean más del 20\% de sus ingresos en pagar la energía, se dirá que dichos hogares se encuentran en situación de pobreza energética severa (Welsh Assembly Government, 2010).

En 2003 el Fuel Poverty Commitment for Wales adoptó el objetivo de que, dentro de lo razonablemente factible, ningún hogar se encontrase en situación de pobreza energética para 2018. De igual manera en 2010, la Estrategia de Pobreza energética señaló la obligación del Gobierno Gales de erradicar la pobreza energética para 2018.

El paso del tiempo ha mostrado que se ha logrado una mejora de los niveles de pobreza energética pero no se va a conseguir erradicarla tal y como se había planteado en 2018 (NEA, 2017). Para ello, se requeriría una nueva estrategia y nuevos objetivos más ambiciosos, por lo que en 2015 se planteó que NEA debería hacer nuevas recomendaciones para cinco años a partir de 2016.

Así, en 2016, había 291.000 hogares en pobreza energética frente a los 305.000 de 2015, lo que supone una mejora del 24 al $23 \%$. Esto supone un pequeño avance si se tiene en cuenta que en 2008, cuando se realizó la última encuesta, el 26\% de los hogares galeses estaban en pobreza energética. El 5\% de los hogares galeses emplean electricidad en calefacción frente al 79\% que emplea gas (CommitTeE on CLimate CHANGE, 2017).

En la actualidad, existen dos esquemas de eficiencia energética doméstica, en funcionamiento en Gales, dentro del programa Welsh Government's Warm Homes Programme, en relación con las políticas de RU Green Deal y ECO. Estos esquemas son: Warm Homes Nest y Warm Homes Arbed . El primero se inició en abril de 2011, tiene ya casi siete años y ha logrado importantes éxitos (BRIDGEMAN et al., 2016). Actualmente, continúa ofreciendo un paquete de mejora de la eficiencia energética sin coste para los hogares. El objetivo de la política son las personas con bajos ingresos que viven en viviendas energéticamente ineficientes (BRIDGEMAN et al., 2016). Este programa ofrece servicios de asesoramiento y apoyo para ayudar a reducir las facturas energéticas y es compatible con otros programas gratuitos o subsidiados.

Por su parte, el programa Warm Homes Arbed tiene como objetivo las áreas más deprimidas de Gales, que se han identificado empleando el Welsh Index of Multiple Deprivation (WIMD). Los hogares no pueden aplicar directamente por el apoyo, sino a través de entidades locales. Su objetivo es erradicar la pobreza energética y promover el desarrollo económico y la regeneración de Gales.

El Welsh Government's Warm Homes Programme cuenta en la actualidad con unos fondos de unos 26 millones de libras al año y está comprometido hasta 2021. Se espera que 25.000 viviendas reciban ayudas de este fondo para mejorar la eficiencia energética los próximos años.

El Gobierno galés se encuentra ahora revisando los planes de eficiencia energética a futuro para los hogares en pobreza energética. En este sentido, cualquier esquema que se desarrolle en Gales para mejorar la eficiencia energética debería considerar hogares con las siguientes características: ingresos relativamente reducidos (por debajo del $60 \%$ de la mediana), alguna vulnerabilidad adicional (adultos con más de 65 años, niños, personas con invalidez, enfermedad a largo plazo, cardíaca o pulmonar), vivienda ocupada por el propietario o alquilada por un propietario privado y vivienda ineficiente (E, F o G). En este sentido, es necesario que para cada área de Gales se trate el tema de las casas frías y de la pobreza energética (NEA, 2017).

3.3. Escocia

En Escocia, se considera que un hogar se encuentra en situación de pobreza energética si, para mantener un régimen de calor satisfactorio, necesitase gastar más del $10 \%$ de sus ingresos en combustible en todo el hogar (ScotTish EXEcutive, 2002, en Pye et al., 2015a). Las principales diferencias en la definición escocesa se deben a interpretaciones alternativas de lo que suponen un calor adecuado, enfermedades a largo plazo, hogares con discapacidades, o temperatura adecuada $23^{\circ}$, frente a los $21^{\circ}$ de Inglaterra, etc.

El Gobierno escocés se había comprometido a erradicar la pobreza energética dentro de lo posible para noviembre de 2016 ${ }^{29)}$ (ScoTTISH GovERNMENT. RIAGHALTAS NA H-ALBA, 2017), objetivo que no se ha logrado puesto que, en 2014, la pobreza energética afectaba a 845.000 hogares frente a los 748.000 de 2015, reducción que se debe, en gran medida, a las reducciones de precios de los combustibles y a las mejoras de la eficiencia energética de los hogares $^{30}$ (NEA, 2017). En 2013 la pobreza energética alcanzaba a 860.000 hogares.

El número de hogares en pobreza energética severa, que consumen más del $20 \%$ de sus ingresos en energía, afectaba a 203.000 hogares en 2015 , frente a los 229.000 de 2014 (NEA, 2017). La mayor parte de los hogares escoceses (78\%) emplea gas en la calefacción y el 13\% emplean la electricidad (Committee on Climate Change, 2017).

Uno de los principales problemas en Escocia es la pobreza energética rural. Ello es debido a una combinación de factores que incluye peores niveles de conexión a las redes de gas, temperaturas más frías y condiciones meteorológicas más duras, mayores precios de la electricidad y falta de iniciativa de los consumidores a cambiar de suministrador (CommitTeE on Climate Change, 2017).

En efecto, en Escocia uno de los principales problemas es la diferencia de precios de la energía respecto a las otras naciones. Ante esto se plantea la necesidad de que el precio de la energía sea el mismo independientemente de la ubicación del consumidor doméstico dentro del país (HANSARD Parliament, 2017). 
Además, existen factores sobre los que el Gobierno escocés no tiene competencia y que son de gran importancia para mitigar la pobreza energética. Así, el acceso a las redes de gas debería contar con un mejor servicio por parte de los programas nacionales. Este es un problema que afecta al 34\% de los hogares escoceses, al 56\% en las Highlands y al 59\% en las Western Isles, llegando al 65\% en Orkney.

En este contexto, en Escocia los consumidores pagan facturas superiores a otros territorios del RU como consecuencia de los sobrecargos por la distribución de electricidad ${ }^{31)}$, por no tener acceso a las redes de gas (lo que obliga a utilizar combustibles más caros), y porque hacen más uso de la energía debido a las condiciones climatológicas. Debido a ello, a pesar del esfuerzo por introducir mejoras en eficiencia energética, hay cuestiones que solo con la intervención del Gobierno de RU se pueden resolver, como la creación de un mercado nacional, que evite que la gente se vea penalizada por el lugar en donde residen.

En lo que a eficiencia energética se refiere, también es necesario avanzar en la mejora del uso de la energía. En este sentido, el Home Energy Scotland (HES) ofrece visitas domiciliarias a hogares vulnerables. Como resulta de gran valor trabajar con organismos locales, más cercanos al problema (ScotTish Government, 2017), el Gobierno consideró ampliar este servicio, lanzando el plan HES Homecare en febrero 2017, a revisar anualmente.

Escocia cuenta además de con el programa Energy Company Obligation (ECO) con el Scotland's Home Energy Efficiency Programmes ( HEEPs ). Bajo el HEEPs the Warmer Homes Scotland Scheme se conceden ayudas para la mejora de la EE a hogares escogidos. Consiste en un conjunto de programas que incluyen los Area Based Schemes (ABS) , un programa denominado Warmer Homes for Scotland y dos programas de préstamos (NEA, 2017). Se estima que estas mejoras han permitido un ahorro de $350 £$ en la factura energética al año. HEEPs también ofrece mejoras en la eficiencia energética a través de las autoridades locales, mediante programas basados en el aislamiento de las paredes en áreas con elevados niveles de pobreza energética (Committee on Climate Change, 2017).

Asimismo, en junio de 2015 el Gobierno escocés anunció su intención de hacer de la eficiencia energética una prioridad de infraestructura nacional. Emplea como pilar el programa Scotland's Energy Efficiency Programme (SEEP), un plan a 15-20 años que ofrecerá apoyo para mejorar la EE. El SEEP se lanzará en 2018 y tendrá un apoyo de 500 millones de libras de fondos públicos durante cuatro años (NEA, 2017). Se espera que cuando el programa se encuentre totalmente operativo, genere unos 4.000 empleos por año.

La reciente transferencia de competencias de los programas Winter Fuel Payments y Cold Weather Payments se entiende que facilitará la oportunidad de usarlos apropiadamente desde la Administración escocesa para abordar mejor las desigualdades.

Para otoño de 2017, se esperaba que se realizara una consulta para el desarrollo de una nueva estrategia a largo plazo y avanzar en el desarrollo de la Warm Homes Bill para 2018.

\subsection{Inglaterra}

En 1996 en Inglaterra había cinco millones de hogares en pobreza energética. Esta cifra cayó a un millón en 2003/2004. Sin embargo, en 2009, las cifras volvieron a aumentar rápidamente, llegando a los cuatro millones de hogares.

Desde 2011, la pobreza energética se mide, en Inglaterra, con el indicador LIHC. En 2013, el Gobierno de coalición de Westminster, siguiendo al profesor Hills, modificó el calendario de erradicación de la pobreza energética así como su definición. Dicho año, se enmendó la Warm Homes and Energy Conservation Act de 2000 con la Energy Act de 2013, estableciéndose nuevos objetivos de mejora de la EE en los hogares debiendo tener, los hogares pobres, una categoría E en 2020, D en 2025 y C en 2030 (NEA, 2016) y ( HM GoverNMENT, 2015).

Este objetivo resulta un reto si se tiene en cuenta que de acuerdo con las estadísticas, en 2015, únicamente el 8\% de los hogares pobres vivía en viviendas clasificadas como A, B o C, respecto al 36\% de la población no pobre (DePARTMENT For BusinESS, ENERGY AND INDUSTRIAL STRATEGy, 2017).

Según este indicador, la pobreza energética afectaba a unos 2,35 millones de hogares en 2013, lo que suponía aproximadamente el 10,4\% de los hogares. En 2014, el número de hogares ingleses en pobreza energética ascendía a 2,38 millones, el 10,6\% del total. En 2015, esta cifra aumentó a 2,5 millones, afectando al $11 \%$ de los hogares.

Tabla 4. Número de hogares en pobreza energética (millones)

\begin{tabular}{|c|c|c|c|c|c|c|c|c|c|c|c|c|}
\hline & 2003 & 2004 & 2005 & 2006 & 2007 & 2008 & 2009 & 2010 & 2011 & 2012 & 2013 & 2014 \\
\hline $\begin{array}{ll}\text { Número de hogares } \\
\text { en } & \text { pobreza } \\
\text { energética } & \end{array}$ & 2,41 & 2,44 & 4,39 & 2,28 & 2,38 & 2,51 & 2,57 & 2,49 & 2,43 & 2,36 & 2,35 & 2,38 \\
\hline $\begin{array}{l}\text { Porcentaje de } \\
\text { hogares en pobreza } \\
\text { energética (\%) }\end{array}$ & 11,6 & 11,6 & 11,3 & 10,7 & 11,1 & 11,7 & 11,9 & 11,5 & 11,1 & 10,8 & 10,4 & 10,6 \\
\hline
\end{tabular}

Fuente: DECC, 2016.

En 2015, el fuel poverty gap en términos reales fue de $353 £$ (371£ en 2014 y $379 £$ en 2013), una reducción del 5,6\% respecto del año anterior, para un $11 \%$ de los hogares ingleses. Debido a la naturaleza relativa del indicador, los niveles de pobreza energética se mantienen estables en el tiempo.

La mayor parte de los hogares ingleses (86\%) emplea gas en la calefacción frente al 8\% de los hogares que emplean la electricidad (CommitTeE oN Climate Change, 2017).

Hay una amplia gama de ayudas para aliviar la pobreza energética en Inglaterra. Existe ayuda directa para pagar las facturas como el Warm Home Discount o el Winter Fuel Payment medidas de ahorro energético a través del paquete Energy Company Obligation (ECO) y el Green Deal ( HM Government , 2015). Sin embargo, Inglaterra, es la única nación de Gran Bretaña sin un fondo gubernamental de eficiencia energética propio en paralelo con el programa ECO. No obstante, para cubrir la falta de calefacción durante la transición del programa ECO, se requieren fondos para cubrir las crisis que puedan surgir y proteger a los hogares en pobreza energética, así como a aquellos hogares sin acceso a gas cuya salud se encuentra en riesgo (NEA, 2017).

Además, el National Institute for Health and Care Excellece (NICE) desarrolló unas recomendaciones para evitar el exceso de muertes en invierno y los riesgos para la salud asociados a las viviendas frías, como desarrollar una estrategia, identificar a las personas con problemas de salud y que pueden sufrir frío, formar a las personas que visitan hogares para que puedan informar a aquellos hogares con necesidades de energía, formar a los profesionales en EE para ayudar a los hogares vulnerables, etc. (NICE, 2015).

En Irlanda del Norte se está planteando la posibilidad de seguir dichas recomendaciones. Escocia no considera por el momento la posibilidad de adoptarlas. En Gales, tampoco, pero se están tomando medidas para relacionar los problemas de salud y calefacción en las viviendas (NEA, 2017). En todo caso, la National Energy Action está recomendando la aplicación de estas medidas NICE a todas las administraciones.

Así, Inglaterra, con una población de 55 millones de personas en 2016, tenía el 84,6\% de la población total del Reino Unido y podría decirse, en base a sus estadísticas, que ha profundizado en gran medida en el problema de la pobreza energética. En efecto, las estadísticas presentadas anualmente por el Department for Business, Energy and Industrial Strategy muestran que no solo se ha evolucionado en la medición de la pobreza energética (con sus pros y contras) sino que cuenta con un análisis muy detallado de las viviendas del territorio. 
A modo de ejemplo, dispone de datos relativos a la antigüedad de las viviendas, al régimen de posesión de las mismas, a la calidad de la vivienda, a los tipos de hogares en función de diferentes variables (edad, número de niños...), al equipamiento de la vivienda (calderas centralizadas), etc.

\section{Figura 2. Parámetros para valorar un hogar en pobreza energética en Inglaterra}

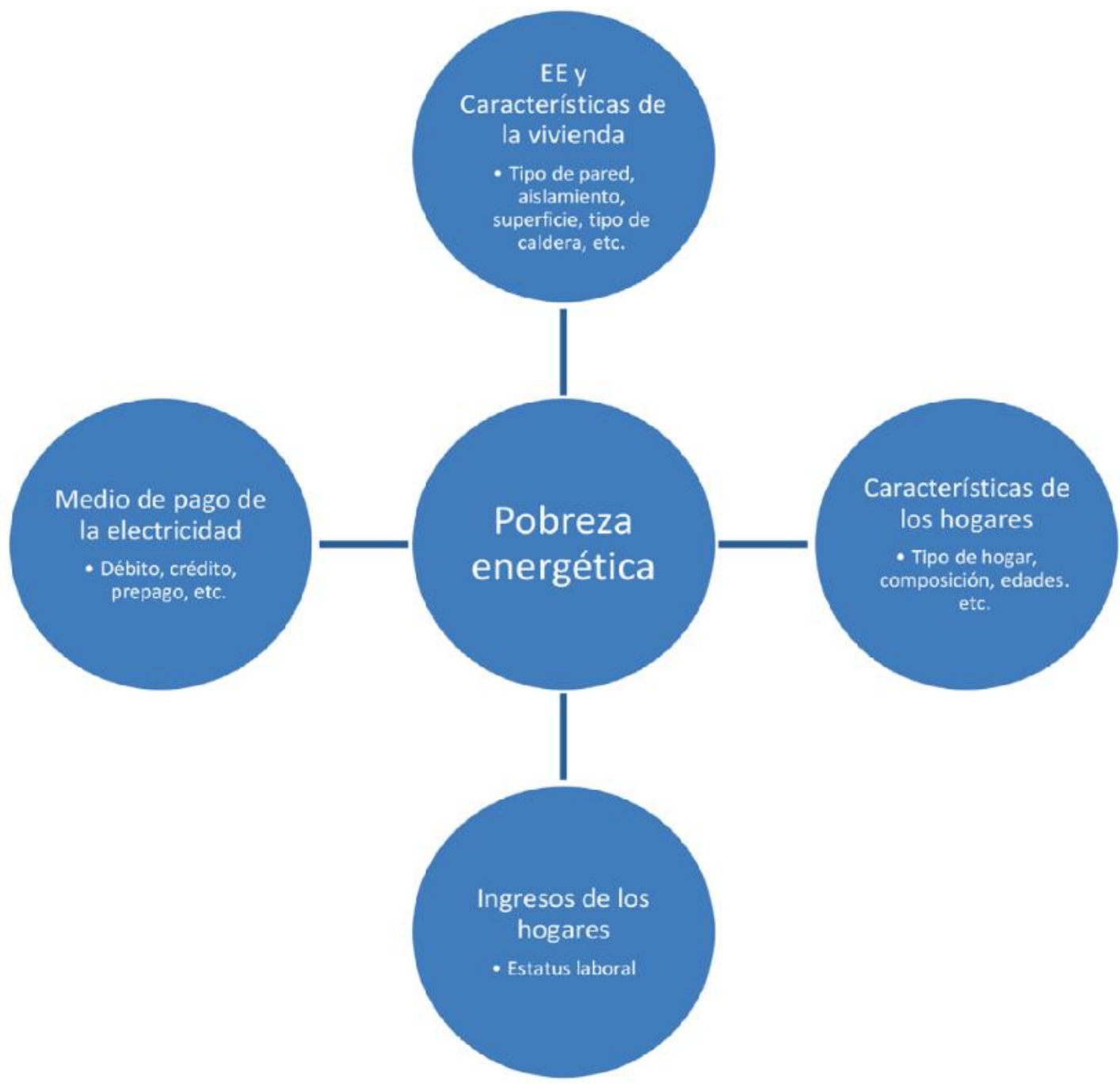

Fuente: elaboración propia a partir de Department for Business, Energy and Industrial Strategy, 2016 y 2017.

\section{CONCLUSIONES}

La pobreza energética es una realidad no solo en economías menos desarrolladas, sino también en Europa. Los 54 millones de ciudadanos europeos, que en 2012 no tenían un adecuado acceso a los recursos energéticos es la muestra de las dimensiones de este problema. Sin embargo, la normativa comunitaria actual permite a los Estados miembros eludir su responsabilidad, por lo que muchos consumidores quedan desprotegidos.

Un primer paso para poder abordar la pobreza energética, a nivel europeo, consistiría en reconocer la existencia del problema y, por ende, darle una definición consensuada al concepto. En base a la literatura se puede observar que existe una gran variedad de conceptualizaciones y circunstancias diferentes. Es también conveniente que el concepto de pobreza energética tenga en cuenta no solo el gas y la electricidad, sino también otros combustibles y sea un concepto que pueda adaptarse a las condiciones de cada país. En todo, caso disponer de una definición, aun no siendo está compartida en todos los países es un importante avance para enfrentar el reto que supone la pobreza energética, tal y como se ha puesto de manifiesto en Reino Unido.

En Reino Unido, como ejemplo de país que se podría decir líder en la lucha contra la pobreza energética, se han desarrollado dos definiciones diferentes, una de ellas más reciente y únicamente aplicada en Inglaterra. La primera supone que un hogar sufre pobreza energética si requiere gastar más del $10 \%$ de sus ingresos en combustible para calentarse. La segunda definición plantea que un hogar se encuentra en situación de pobreza energética si sus ingresos se encuentran por debajo de la línea de pobreza (tomando en consideración costes de energía) y sus costes de energía son superiores a lo que es habitual para ese tipo de hogar.

Se trata de definiciones que tienen sus limitaciones, pero que permiten a los Gobiernos acotar en cierta medida el problema, detectar al menos una parte de la población afectada y tomar decisiones para su resolución. Sin estas definiciones resultaría más complejo afrontar el reto que supone la pobreza energética.

Parámetros o indicadores que pueden servir también para describir y/o medir la pobreza energética en la UE son: la incapacidad de calentar adecuadamente el hogar, los retrasos en los pagos de las facturas energéticas y la presencia de determinadas características negativas en las 
viviendas. No obstante, la casuística de la pobreza energética es suficientemente amplia como para que no exista una solución adaptada a todos los casos. Como consecuencia, es conveniente desarrollar una estrategia integrada, que no solo se fije en lograr precios asequibles a la energía, sino que garantice unos ingresos adecuados para cubrir las facturas y ayudar a reducir el consumo a través de la mejora de la eficiencia energética.

Teniendo en cuenta que el aumento del precio de la energía, en general, no es la única causa de la pobreza energética, y que cada país/territorio presenta su propia casuística (países de Europa del Este, del Mediterráneo u otros), son muchas las medidas que se pueden implementar. Entre estas, algunas son a corto plazo como la concienciación e información, la protección del consumidor ante cortes de electricidad o la concesión de ayudas para afrontar los pagos de las facturas. De igual manera, están las medidas que ofrecen protección a los consumidores vulnerables en los mercados regulados y permiten su acceso y participación. Todas ellas son, por su naturaleza, medidas a corto plazo que reducen la carga o garantizan un suministro continuado ante situaciones de impago. En las medidas para consumidores vulnerables suelen jugar un papel clave los reguladores y las compañías eléctricas.

A más largo plazo, se encuentran medidas como la mejora de la eficiencia energética, reconocida como una de las medidas más efectivas, que debe de reconocerse como pilar en la lucha contra la pobreza energética, y sostenible para la reducción de la factura eléctrica. Supone grandes inversiones que permitirían resolver gran parte de los problemas y que además, podrían generar empleo, mejorar la salud y la calidad de vida, renovar distritos pobres, ofreciendo una señal de inclusión social... en un contexto en el que esto se convierte en un importante valor.

Para afrontar la pobreza energética, los principales actores suelen ser el Gobierno o la correspondiente agencia nacional de energía. No obstante, la experiencia recabada en Reino Unido en general, y en Inglaterra en particular, pone de manifiesto la importancia de contar con las instituciones locales para poder resolver un problema que no necesariamente se detecta desde el exterior, sino a través de indicios. De igual manera, la colaboración con los reguladores, los propios consumidores y las compañías energéticas puede resultar clave para detectar dichos indicios y poder tomar medidas (por ejemplo en el caso de la autodesconexión de la red).

En todo caso, es conveniente que se estudie el impacto de las medidas aplicar a priori y que se establezcan políticas estables en el tiempo, lo que permitiría generar confianza entre los agentes involucrados.

Además, resulta aconsejable armonizar los datos de modo que se pueda desarrollar indicadores de pobreza energética que sean comparables entre sí, a diferencia de lo que sucede en RU. Asimismo, y en este ámbito estadístico, sería conveniente mejorar la forma de recopilación de información y de igual manera tratar de homogeneizar el procedimiento.

La formación y preparación de los voluntarios que permiten acceder al conocimiento del problema de la pobreza energética es fundamental para tener un mayor conocimiento de la situación y poder acercarse a esta realidad.

\section{BIBLIOGRAFÍA}

Atanasiu, B.; Kontonasiou, E. y Mariottini, F. (2014). Alleviating Fuel Poverty in the EU . BPIE. http://bpie.eu/wp-content/uploads/2015/10/Alleviatingfuel-poverty.pdf

Austin, P. (2016). Fuel poverty in Northern Ireland . NEA. http://www.nea.org.uk/wp-content/uploads/2016/01/Pat-Austin-NEA-Northern-Ireland2.pdf

Bouzarovski, S. y Petrova, S. (2015). A global perspective on domestic energy deprivation: Overcoming the energy povertu-fuel poverty binary. Energy Research \& Social Science 10, 31-40. www.elsevier.com/locate/erss

Bridgeman, T.; Thumim, J.; Asher, M.; Hodges, N.; Searby, G.; Morris, P.; Center for Sustainable Energy (2016). Understanding the characteristics of low income households most at risk from living in cold homes. Final report to the Welsh Government: Main report.

Committee on Climate Change (2017). Energy prices and bills. Impacts of meeting carbon budgets . www.theccc.org.uk

Damianova, Z. (2015). Energy Poverty . Executive summary. CASI Policy Brief file:///C:/Users/asun.angulo/Downloads/casi-pb-7-2015-final.pdf

DECC (2016). Fuel poverty. Methodology Handbook

https://www.gov.uk/government/uploads/system/uploads/attachment data/file/557403/Fuel Poverty Methodology Handbook 2016 updated 23.09.2C

Delebarre, J. y Hough, D. (2017). The current energy markets reform in Great Britain . House of Commons Library. www.parliament.uk/commonslibrary

Department fOR Business, Energy \& Industrial Strategy (2016). Annual fuel poverty statistics report, 2016 (2014 data). England. https://www.gov.uk/government/uploads/system/uploads/attachment data/file/557400/Annual Fuel Poverty Statistics Report 2016 revised 30.09.2016.pdf

Department for Business, Energy \& Industrial Strategy (2017). Annual fuel poverty statistics report, 2017 (2015 data). England. https://www.gov.uk/government/statistics/annual-fuel-poverty-statistics-report-2017

Department for Social Development (2011). Warmer Healthier Homes. A new fuel poverty strategy for Northern Ireland . www.dsdni.gov.uk

Department of the Economy (2016). Consultation paper. EnergyWise Scheme Proposals. http://fuelpovertyni.org/wp-content/uploads/EnergyWiseConsultation-May-2016.pdf

Directiva 2003/54/CE del Parlamento europeo y del Consejo de 26 de junio de 2003, sobre normas comunes para el mercado interior de la electricidad y por la que se deroga la Directiva 96/92/CE.

Directiva 2003/55/CE del Parlamento europeo y del Consejo de 26 de junio de 2003, sobre normas comunes para el mercado interior del gas natural y por la que se deroga la Directiva 98/30/CE.

Directiva 2009/72/CE del Parlamento europeo y del Consejo de 13 de julio de 2009, sobre normas comunes para el mercado interior de la electricidad y por la que se deroga la Directiva 2003/54/CE.

Directiva 2009/73/CE del Parlamento europeo y del Consejo de 13 de julio de 2009 sobre normas comunes para el mercado interior del gas natural y por la que se deroga la Directiva 2003/55/CE.

Directiva 2012/27/UE del Parlamento europeo y del Consejo de 25 de octubre de 2012, relativa a la eficiencia energética, por la que se modifican las Directivas 2009/125/CE y 2010/30/UE, y por la que se derogan las Directivas 2004/8/CE y 2006/32/CE.

DSD (2014). Summary of responses to public consultation "From Fuel poverty to affordable warmth". http://www.ninga.co.uk/DataEditorUploads/affordable-warmth-consultation.pdf

Dubois, U. y MeIER, I. (2014a). Energy poverty in France and Germany: perceptions and policy approaches . 


\section{file://C:/Users/asun.angulo/Downloads/dubois2013abstract.pdf}

Dubois, U. y MeIER, I. (2014b). Households facing constraints. Fuel poverty put into context. EWI working paper, N. 14/07. www.ewi.uni-koeln.de EAPN(2010). EAPN Working paper on energy poverty. European anti-poverty network. Bruselles. http://www.eapn.eu/wpcontent/uploads/2010/03/2010-eapn-working-paper-on-energy-poverty.pdf

EC(2010). An energy policy for customers. Commission Staff Working Paper, EC, Brussels, 11.11.2010. https://ec.europa.eu/energy/sites/ener/files/documents/sec\%282010\%291407.pdf

ECONOMICS FOR ENERGY (2015). Pobreza Energética en España .

ENERGY UK (2017a). Prepayment meters. www.energy-uk.org.uk/policy/prepayment-meters.html

ENERGY UK (2017b). Prepayment meter principles 2016. https://www.energy-uk.org.uk/files/docs/PPMPrinciples-2016.pdf

EPSU , EAPN (2017). Right to energy for all Europeans. http://www.energy-democracy.net/?p=969

Hansard Parliament (2017). Fuel poverty. Volume 623. https://hansard.parliament.uk/commons/2017-03-21/debates/9496E093-111E-49AC-A52821C83509DC4D/FuelPoverty

House of Commons LibraRy (2017). Debate pack. Fuel poverty. www.parliament.uk/commons-library

Koh, L.; Marchand, R.; Genovese, A. y Brennan, A. (2012). Fuel poverty. Perspectives from the front line . The University of Sheffield. Center for energy, environment and sustainability: Fuel poverty series. https://www.sheffield.ac.uk

Moore, R. (2012). Definitions of fuel poverty: Implications for poverty. Energy Policy DOI: 10.1016/j.enpol.2012.01.057 (http://onpe.org/sites/default/files/pdf/documents/rapports partenaires/definition ep.pdf)

NEA(2016). UK Fuel Poverty Monitor 2015-2016. A review of progress across the nations , 2016 http://www.nea.org.uk/wpcontent/uploads/2016/05/FPM 2016 low res.pdf

NEA (2017). UK Fuel Poverty Monitor 2016-2017. A review of progress across the nations , 2016 http://www.nea.org.uk/

NICE(2015). Excess winter deaths and illness and the health risks associated with cold homes . https://www.nice.org.uk/guidance/ng6

NIHE's ReseARch Unit(2017). Northern Ireland. House condition Survey . Preliminary report 2016. http://www.nihe.gov.uk/nihcs_2016_preliminary_report.pdf

Office of National Statistics (2017). Population estimate analysis Mid-2016. Release $22 \quad$ June 2017 https://www.ons.gov.uk/peoplepopulationandcommunity/populationandmigration/populationestimates/datasets/populationestimatesanalysistool

Plataforma contra la Pobreza (2011). La Plataforma Europea contra la Pobreza y la Exclusión Social: Un marco europeo para la cohesión social y territorial. $\quad$ http://www.google.es/url?

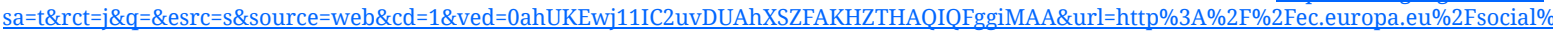

Pye, S.; Dobbins, A.; BAfFert, C.; JuRICA BRAjKović, I.G.; De Miglio, R. y DeAne, P. (2015a). Energy poverty and vulnerable consumers in the energy sector
across https://ec.europa.eu/energy/sites/ener/files/documents/INSIGHT_E_Energy\%20Poverty\%20-\%20Main\%20Report_FINAL.pd

Pye, S.; Dobbins, A.; Baffert, C.; Jurica Brajković, I.G.; De Miglio, R. y Deane, P. (2015b). Energy poverty and vulnerable consumers in the energy sector across the EU: analysis of policies and measures: Appendices to main report . Insight_E. www.insightenergy.org

Scottish Government. Riaghaltas na H-Alba (2017). The Scottish Government's response to reports by the Scottish Fuel Poverty Strategic Working Group and the Scottish Rural Fuel Poverty. http://www.gov.scot/Publications/2017/03/1009/4

ScotTish Government (2017). Fuel poverty: Scottich Government response to working group reports. http://www.gov.scot/Publications/2017/03/1009/4

Thomson, H.; Snell, C. y Liddell, C. (2016). Fuel poverty in the European Union: a concept in need of definition? People, Place and Policy 10 (1) 5-24. DOI: 10.3351/ppp.0010.0001.0002 http://extra.shu.ac.uk/ppp-online/wp-content/uploads/2016/04/fuel-poverty-european-union.pdf

Tirado Herrero, S.; Jiménez Meneses, L.; López Fernández, J.L.; Perero Van Hove, E.; Irigoyen Hidalgo, V.M. y Savary, P. (2016). Pobreza, vulnerabilidad y desigualdad energética. Nuevos enfoques de análisis. España 2006-2016 . Madrid: Asociación de Ciencias Ambientales. www.cienciasambientales.org.es

\section{FOOTNOTES}

En Thomson et al., (2016).

Tres son los indicadores para medir la pobreza: la tasa de riesgo de pobreza (una vez percibidas las transferencias sociales), el índice de privación material y el porcentaje de personas que viven en hogares con intensidad de trabajo muy baja 
Los hogares con reducidos ingresos toman diferentes medidas como reducir el gasto en bienes no esenciales, en comida, en calefacción y en otros (Dubois y MEIER, 2014b).

5

Bouzarovski y Petrova (2015) en Tirado Herrero et al. (2016).

Estos tres periodos se encuentran identificados en Tномsоn et. al (2015).

Sobre normas comunes para el Mercado interior de la electricidad y por la que se deroga la Directiva 96/92/CE.

8

Sobre normas comunes para el mercado interior del gas natural y por la que se deroga la Directiva 98/30/CE.

9

"40. "Energy poverty" means the situation where the members of a household cannot afford to heat their home to an acceptable standard, based on the levels recommended by the World Health Organization".

"41. "affordable price" means a price defined by Member States at national level in consultation with national regulatory authorities, social partners and relevant stakeholders while taking account of the definition of energy poverty provided for in point 40» (European Parliament, 2008a: 150).

EESC: European Economic and Social Committee.

Sobre normas comunes para el mercado interior de la electricidad y por la que se deroga la Directiva 2003/54/CE.

13

Sobre normas comunes para el mercado interior el gas natural y por la que se deroga la Directiva 2003/55/CE.

Relativa a la eficiencia energética, por la que se modifican las Directivas 2009/125/CE y 2010/30/UE y por la que se derogan las @ Directivas 2004/8/CE y 2006/32/CE.

En este caso, se requiere la cooperación entre reguladores y empresas suministradoras, y se establecen diferentes criterios de selección de los grupos.

Existen importantes programas de eficiencia energética en países de Europa del Este, que cuentan con muchas viviendas de la era soviética, con las categorías energéticas más ineficientes.

BAKER (2014) en PYE et al. (2015a).

Todas las regiones se pueden beneficiar de los ERDF y de los ESF (Fondos Estructurales). Solo las regiones en desarrollo se pueden beneficiar de los Fondos de Cohesión. 
La incapacidad de pagar las facturas energéticas genera estrés y preocupaciones, así como riesgo de desconexión. Puede ocasionar enfermedades físicas y psicológicas y contribuir a la exclusión social.

En el documento Pobreza Energética: un marco para futuras acciones

El indicador del 10\% se empleó en Inglaterra entre 2001 y 2011

A modo de ejemplo, un hogar con un nivel de ingresos determinado no tendrá el mismo disponible si forma parte de él una única persona o cuatro.

A lo largo de los últimos años se han desarrollado otros indicadores que miden la pobreza energética y que se han descrito en el artículo de Pedro González sobre la Vulnerabilidad Energética y el Bono Social , recogido también en este monográfico.

El 16\% de los consumidores domésticos utilizan contadores prepago, que pueden ser para electricidad y gas. En general se trata de consumidores vulnerables, que pagan más por la electricidad de lo que podrían pagar con contadores tradicionales. Sin embargo, estos contadores prepago les permiten gestionar su consumo y sus finanzas, controlando los gastos en energía. Los suministradores no pueden instalar estos contadores si no logran las condiciones de seguridad necesarias y deben emplear los datos obtenidos de estos para analizar las desconexiones voluntarias (ENERGY UK, 2017b).

En este sentido, los suministradores del RU reconocen la necesidad de proteger a los consumidores vulnerables y evitar su desconexión, de esta manera, si un suministrador identifica a un consumidor de este tipo, tendrá como prioridad reconectarlo. La desconexión es únicamente un último recurso que sigue a un largo proceso de recuperación de una deuda del suministrador. Antes de desconectar a un consumidor, el suministrador debe conocer las circunstancias del consumidor y establecer un plan de pago adecuado (ENERGY UK, 2017a).

Consiste en un pago directo a todos los hogares que cuentan con un miembro de 60 años o más.

Se trata de un pago realizado a un conjunto de individuos escogidos cuando la temperatura se prevé que baje de los $0^{\circ} \mathrm{C}$ durante un periodo de siete días o más. En la actualidad el pago es de unos 30 euros por cada semana de mal tiempo.

Entre diciembre 2009 y diciembre 2010 el precio del fuelóleo para calefacción subió un 30\%.

En Irlanda del Norte, se ha señalado que los propietarios deben responsabilizarse del mantenimiento de las viviendas y de su eficiencia energética (DSD, 2014)

En la actualidad el objetivo de erradicar la pobreza se ha pospuesto a 2021.

Desde 2003, ha mejorado la calificación de las viviendas, aumentando en un 37\% las clasificadas como A, B, C y D.

Los cargos por la distribución de electricidad para el norte de Escocia son un 84\% más elevados que para Londres. 
La Autora desea agradecer a Eloy Álvarez Pelegry su confianza depositada para tratar este tema y a Asun Angulo Mansilla su inestimable ayuda para abordar este tema tan complejo e interesante. 